\title{
Adenosine Triphosphate Depletion Reverses Sodium-Dependent, Neuronal Uptake of Glutamate in Rat Hippocampal Slices
}

\author{
J. E. Madl and K. Burgesser \\ Department of Anatomy and Neurobiology, Colorado State University, Fort Collins, Colorado 80523
}

\begin{abstract}
Extracellular accumulations of excitatory amino acids (EAAs) may mediate ischemic neuronal damage. Metabolic insults can decrease $\mathrm{Na}^{+}$and $\mathrm{K}^{+}$plasma membrane gradients, thereby reducing the driving force for uptake of EAAs into cells by $\mathrm{Na}^{+}$-dependent EAA cotransporters. EAA accumulations could result from decreased uptake and increased release due to reversal of these cotransporters. ATP depletion, uptake, and release of EAAs were measured by HPLC in slices treated with metabolic inhibitors. Inhibition and reversal of cotransporters were determined by uptake or release of $\mathrm{D}, \mathrm{L}$-threo- $\beta$-hydroxyaspartate $(\mathrm{OH}$-Asp), an EAA analog with high affinity for cotransporters. Moderate ATP depletion (7>ATP $\mathrm{nmol} / \mathrm{mg}$ protein $>3$ ) reduced uptake by cotransporters without increasing release of EAAs. When ATP was severely depleted (ATP $<2 \mathrm{nmol} / \mathrm{mg}$ protein), increased release of EAAs and preloaded OH-Asp occurred, consistent with reversal of cotransporters. Release of glutamine and asparagine was not increased, confirming that release was not primarily due to nonselective increased membrane permeability. ATP depletion and ouabain acted synergistically to produce EAA release, strongly suggesting release was largely mediated by inhibition of $\mathrm{Na} / \mathrm{K}$-ATPases. Severe ATP depletion decreased glutamate-like immunoreactivity primarily in axonal terminal-like structures, suggesting release occurred primarily from terminals. Moderate ATP depletion may increase extracellular EAAs by decreasing uptake. Severe ATP depletion may further increase EAAs by reversing uptake, thereby releasing cytosolic neuronal pools of EAAs.
\end{abstract}

IKey words: glutamate release, ischemia, $\mathrm{Na} / \mathrm{K}$-ATPase, Na-excitatory amino acid cotransporter, ATP, hypoglycemia, neuron]

A large body of evidence now supports the concept that increased extracellular concentrations of excitatory amino acids ([EAAs $]_{e}$ ) can contribute to the neuronal death seen in many CNS diseases, including ischemia, hypoglycemia, and epilepsy (Rothman and Olney, 1986; Choi, 1988). Although numerous studies have confirmed that excessive activation of receptors by EAAs can kill neurons (Choi, 1988) and that [EAAs] increase during CNS insults, little is known about the mechanism(s) producing these increases in systems more complex than syn-

\footnotetext{
Received Oct. 27, 1992; revised Mar. 4, 1993; accepted Apr. 29, 1993.

We gratefully acknowledge the competent technical assistance of Donna Gilbertson and Sara Heustis. Support for this work was provided by NIH Grant NS28824 and Colorado State Agricultural Experimental Station Fund 15626.

Correspondence should be addressed to Jim Madl at the above address.

Copyright (c) 1993 Society for Neuroscience $0270-6474 / 93 / 134429-16 \$ 05.00 / 0$
}

aptosomes. The relative importance of increased release in contrast to decreased uptake to the increased [EAAs] that occur during many metabolic insults also remains unresolved.

EAAs are normally transported into neurons and glia against large concentration gradients by $\mathrm{Na}-\mathrm{EAA}$ cotransporters, thereby maintaining low [EAAs] (for discussion, see Erecinska, 1987). These cotransporters utilize $\mathrm{Na}^{+}$and $\mathrm{K}^{+}$gradients to power the electrogenic uptake of glutamate (Glu), aspartate (Asp), and other EAAs across plasma membranes (Bouvier et al., 1992). NaEAA cotransporters are reversible (Erecinska and Dagani, 1990) and, therefore, alterations of $\mathrm{Na}^{+}$and $\mathrm{K}^{+}$gradients as well as membrane potential can affect the rate and direction of EAA transport (Szatkowski et al., 1990). Decreased $\mathrm{Na}^{+}$and $\mathrm{K}^{+}$gradients occur during ATP depletion produced by hypoxia and hypoglycemia (see review by Hansen, 1985). ATP depletion has been suggested to prevent the release of neurotransmitters. However, close examination of the issue suggests that although the $\mathrm{Ca}^{2+}$-dependent component of Glu release is decreased, the $\mathrm{Ca}^{2+}$ independent component is greatly increased by ATP depletion (Kauppinen et al., 1988). $\mathrm{Ca}^{2+}$-independent release may be due to reversal of $\mathrm{Na}^{+}$-dependent EAA uptake mechanisms. Dagani and Erecinska (1987; Erecinska and Dagani, 1990) have hypothesized, based on studies of synaptosomes, that ATP depletion produced by ischemia can inhibit $\mathrm{Na} / \mathrm{K}$-ATPases, resulting in ion gradient reductions and subsequent reversal of ncuronal $\mathrm{Na}-\mathrm{EAA}$ cotransporters.

The sites at which decreased uptake or increased release occurs merit investigation. Glu has several functions in the CNS (Fonnum, 1984), acting as an excitatory transmitter and as a major metabolic fuel in cultured astrocytes and, to a lesser extent, in some types of cultured neurons (Hertz et al., 1988). Several lines of evidence suggest EAA metabolism is highly compartmentalized in the CNS. Studies employing labeled precursors (Van den Berg, 1978) and immunocytochemical localization of EAAs (Ottersen et al., 1990) or enzymes involved in their synthesis and catabolism (Wenthold et al., 1986; Madl et al., 1988) suggest EAA metabolism differs greatly in glia and neurons and within subcellular compartments. Although ATP depletion has been shown to induce EAA release from synaptosomes, the relative contributions of glia and other regions of neurons to EAA release have not been reported in a system with intact architecture.

The relationships between inhibition of $\mathrm{Na} / \mathrm{K}$-ATPases, reversal of $\mathrm{Na}-\mathrm{EAA}$ cotransporters, and increases in [EAAs] during ATP depletion were therefore investigated in hippocampal slices, a model system with intact neuronal and glial compartments. Transport of $\mathrm{D}, \mathrm{L}$-threo- $\beta$-hydroxyaspartate $(\mathrm{OH}$-Asp) was used to provide a novel, selective measure of cotransporter activity. Novel immunocytochemical studies of Glu redistribution 
were also performed to examine sites of EAA release. Several questions of importance to understanding the pathophysiology of CNS metabolic insults are addressed by these studies. Is ATP depletion a common mediator of metabolic insult-induced increases in [EAAs $]_{c}$ ? Are increased [EAAs] the result of altered cotransporter activity or merely nonselectively increased membrane permeability? If accumulations are due to altered cotransporter activity, several questions arise. Are the increases of [EAAs] due to both decreased uptake and increased release of EAAs, and does either of these means of increasing [EAAs]. predominate during milder insults? Are changes in cotransporter activity mediated by inhibition of $\mathrm{Na} / \mathrm{K}$-ATPases during ATP depletion? Finally, does release of Glu occur selectively from glia, neurons, or subcellular locations such as nerve terminals?

Moderate ATP depletion was found to decrease EAA uptake without releasing EAAs. When ATP was further depleted by several different methods, EAA release was induced. Glu release was greatest from axonal terminal layers and occurred in a manner consistent with inhibition of $\mathrm{Na} / \mathrm{K}$-ATPases with subsequent reversal of $\mathrm{Na}-\mathrm{EAA}$ cotransporters.

\section{Materials and Methods}

Slice preparation. Transverse, $400 \mu \mathrm{m}$ sections of hippocampi were obtained from adult Sprague-Dawley rats essentially by the methods of Whittingham et al. (1984). Slices were washed for $1 \mathrm{hr}$ at room temperature (about $23^{\circ} \mathrm{C}$ ) in Hank's balanced salt solution $\left(1.25 \mathrm{~mm} \mathrm{CaCl}_{2}\right.$, $0.7 \mathrm{mM} \mathrm{MgSO}_{4}, 5.4 \mathrm{mM} \mathrm{KCl}, 0.4 \mathrm{mM} \mathrm{KH}_{2} \mathrm{PO}_{4}, 4.2 \mathrm{~mm} \mathrm{NaHCO}_{3}, 137$ mм NaCl, $0.3 \mathrm{~mm} \mathrm{Na} 2 \mathrm{HPO}_{4}, 5.6 \mathrm{~mm}$ glucose) containing an additional $10 \mathrm{~mm}$ glucose and $10 \mathrm{~mm}$ HEPES, pH 7.3, (HBSS) while being bubbled with $5 \% \mathrm{CO}_{2}, 95 \% \mathrm{O}_{2}$. The $\mathrm{pH}$ of HBSS after equilibration with $5 \%$ $\mathrm{CO}$, was 6.95 , resembling mild tissue acidosis that occurs during ischemia. Decreasing $\mathrm{pH}$ did not significantly increase basal release of EAAs or release produced by ATP depletion unless $\mathrm{pH}$ was below 6.4 (J. E. Madl and K. Burgesser, unpublished observations).

For uptake studies, slices were then loaded with 50 or $100 \mu \mathbf{M ~ D , L -}$ threo- $\beta$-hydroxyaspartate (OH-Asp) in bubbled HBSS or in bubbled HBSS containing additional drugs for $1 \mathrm{hr}$ at room temperature, rinsed in HBSS, homogenized in $0.5 \mathrm{ml}$ of cold $0.3 \mathrm{~N}$ perchloric acid, neutralized with $40 \mu \mathrm{l}$ of $3 \mathrm{M} \mathrm{K}_{2} \mathrm{CO}_{3}$, centrifuged to remove precipitates, and used for determination of adenylates and amino acids. To increase the loading of $\mathrm{OH}$-Asp and other transportable amino acids for studies of heteroexchange, loading was performed at $37^{\circ} \mathrm{C}$.

For release studies, slices were loaded with OH-Asp as described for uptake studies, rinsed in HBSS, and incubated in experimental solutions for $1 \mathrm{hr}$ in $0.5 \mathrm{ml}$ or $4 \mathrm{ml}$ of HBSS in a humidified incubator under room air with an additional $5 \% \mathrm{CO}$, without bubbling, at $37^{\circ} \mathrm{C}$. For studies involving EGTA chelation of $\mathrm{Ca}^{2+}, \mathrm{CaCl}_{2}$ was replaced with 1 mM EGTA in the HBSS. Aliquots of supernatants were collected and appropriately diluted in HBSS for amino acid analyses. Slices were then homogenized as before for HPLC determination of amino acids and adenylates. The amount of protein per slice was determined in the perchloric acid pellet using the Bio-Kad protein assay (Bio-Kad, Kichmond, CA). Only small variations in slice size occurred from a mean of $145 \mu \mathrm{g}$ protein per slice; therefore, mean slice protein was assumed to be $145 \mu \mathrm{g}$ for most experiments.

Slices for immunocytochemical studies were treated as described for release studies, up to the point of homogenization, and then fixed for $1 \mathrm{hr}$ with $4 \%$ paraformaldehyde and $0.3 \%$ glutaraldehyde in phosphatebuffered saline (PBS; pH 7.4).

HPLC determination of amino acids and adenylates. Amino acids were quantified in supernatants and homogenates essentially by the method of Skilling et al. (1988) using a Rainin HPLC system with a Microsorb C18 column and guard column (Rainin Instrument Co., Woburn, MA) and a Spectrovision FD 100 fluorescence detector (Spectrovision, Chelmsford, MA). Modifications of the running conditions consisted of minor changes in the gradient. Flow rate was kept constant at $0.5 \mathrm{ml} / \mathrm{min}$, with initial conditions of $95 \%$ Na-acetate buffer $(0.05$ $\mathrm{M}, \mathrm{pH} 6.05$ ) and $5 \%$ methanol. Methanol was increased to $10 \%$ at 8 $\mathrm{min}, 20 \%$ at $12 \mathrm{~min}, 40 \%$ at $17 \mathrm{~min}, 48 \%$ at $22.5 \mathrm{~min}$, and $90 \%$ at 29 min. OH-Asp was clearly separated from other amino acids under these conditions, with a short retention time of approximately $8.5 \mathrm{~min}$. 1-Aminocyclobutane-trans-1,3-dicarboxylic acid (ADC; Tocris Neuramin, Bristol, England) was also clearly separated from other amino acids with a retention time of approximately $18 \mathrm{~min}$ with this gradient.

Adenylates were determined essentially by the HPLC method of Stocchi et al. (1987).

Immunocytochemical localization of glutamate. Fixed slices were rinsed in PBS and incubated for $15 \mathrm{~min}$ in $3 \% \mathrm{H}_{2} \mathrm{O}_{2}$ to inactivate endogenous peroxidase. Artifacts due to the trauma of slicing are commonly present near the cut face of the transverse slices. To avoid these damaged regions near the edges of the slices, fixed slices were further sectioned by cutting $100 \mu \mathrm{m}$ sections perpendicular to the long axis of the slices using a tissue chopper (see Fig. 1). Free-floating sections were incubated in $0.5 \mathrm{ml}$ of 1:80,000 dilutions of Glu-2, a monoclonal antibody to glutaraldehydefixed glutamate, as previously described (McDonald et al., 1989), in PBS containing $10 \mu \mathrm{g} / \mathrm{ml}$ of a conjugate of aspartate to bovine serum albumin prepared to decrease background staining. After incubation for $1.5 \mathrm{hr}$ in primary antibody, sections were further processed using a Vectastain Elite Kit for mouse primary antibodies (Vector Laboratories, Burlingame, CA) essentially as described in McDonald et al. (1989) with diaminobenzidine as chromogen. Absorption controls were performed as previously described (McDonald et al., 1989) by preincubating the monoclonal antibody with $2 \mu \mathrm{g} / \mathrm{ml}$ of glutamate conjugated to bovine serum albumin. Sections were dehydrated in methanol, cleared in $x y-$ lene, and mounted in Permount.

Density of Glu-like immunoreactivity. Density measurements were performed using an Olympus BH-2 microscope equipped with a Panasonic BD400 CCD and analyzed using NIH IMAGE 1.43 software. The light intensity of the microscope was set to give a mean density of less than 5 gray scale units in all strata of absorption controls. Density measurements were found to be linear up to 180 gray scale units using step wedges. Mean densities were obtained from $60 \mu \mathrm{m}^{2}$ areas from the center of the strata of sections to avoid artifacts near the cut edges. Densities of stratum oriens and stratum moleculare were taken approximately $10 \mu \mathrm{m}$ from the neighboring cell body layer. Densities were taken from three representative slices from at least three different days' experiments for each treatment.

Line fittings and calculations of coefficients of determination $\left(R^{2}\right)$ were obtained using CRICKET GRAPH 1.2 (Cricket Software, Malvern, PA). Analysis of variance was performed using STATWORKs (Heyden and Son, Philadelphia, PA). Newman-Kuels multiple comparison tests were performed using KwIKSTAT (TexaSoft, Cedar Hill, TX)

Drugs and other materials were obtained from Sigma Chemical Co (St. Louis, MO) unless otherwise specified.

\section{Results}

To examine the relationship between ATP depletion and uptake, release, and metabolism of EAAs, inhibitors of diverse metabolic processes were used to reduce the ATP content of hippocampal slices. Effects of ATP depletion on EAA content of both supernatants and homogenates were measured to examine the release of EAAs and to determine whether Glu is catabolized in slices to generate ATP, which has been shown to occur in neuronal and glial cultures (Hertz et al., 1988). To determine whether EAA release could be the result of altered cotransporter activity, uptake and release of $\mathrm{OH}-\mathrm{Asp}$, an EAA uptake inhibitor with high affinity for Na-EAA cotransporters (Anderson et al., 1990; Robinson et al., 1991), were measured.

The ATP content of control slices bubbled with $95 \% \mathrm{O}_{2}, 5 \%$ $\mathrm{CO}_{2}$ in $\mathrm{HBSS}$ was $9.2 \mathrm{nmol} / \mathrm{mg}$ protein $\pm 0.7 \mathrm{SEM}$, with an ATP:ADP ratio of $7.0 \pm 0.5$ SEM and an energy charge (Atkinson, 1968) of $0.87 \pm 0.04$ SEM. These results were similar to those reported by Whittingham et al. (1984)

\section{Moderate ATP depletion reduced EAA uptake}

Metabolic inhibition that depleted ATP to less than $8 \mathrm{nmol} / \mathrm{mg}$ protein decreased EAA uptake by $\mathrm{Na}-\mathrm{EAA}$ cotransporters, measured by decreased slice uptake of OH-Asp. Moderate ATP depletion ( $8 \geq$ ATP nmol/mg $\geq 3$; see Table 1 ) induced by lack 


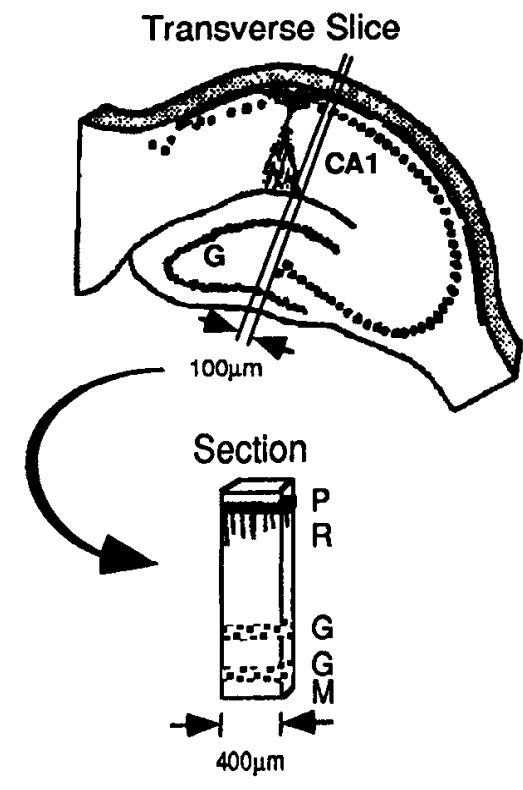

Figure 1. Preparation of sections for immunocytochemistry. Fixed, transverse hippocampal slices were sectioned perpendicular to the cut surface and perpendicular to the long axis of the slice as indicated using a tissue chopper. The resulting $100 \mu \mathrm{m}$ sections used for immunocytochemical localization of Glu contained strata of cells and processes as indicated in CAl and the area dentata of the hippocampal formation. $G$, stratum granulare; $M$, stratum moleculare; $P$, stratum pyramidale; $R$, stratum radiatum.

of bubbling in $\mathrm{O}_{2} / \mathrm{CO}_{2}$ decreased uptake of $\mathrm{OH}$-Asp by $80-90 \%$ without greatly increasing release of endogenous Glu (Fig. 2). As seen in Figure 2, similar decreases in uptake occurred when mild hypoxia due to lack of bubbling was combined with either the Krebs cycle inhibitor arsenite (Banks et al., 1976) or the electron transport inhibitor rotenone (Kauppinen and Nicholls, 1986). Lack of a large release of endogenous Glu was evident by the retention of Glu in ATP-depleted slices. Release of Glu was not quantifiable in uptakc studics involving loading of $\mathrm{OH}$ Asp due to the large amounts of OH-Asp (50-100 $\mu \mathrm{M})$ present in the supernatants. These large amounts of OH-Asp competed with Glu for derivitization with $o$-phthalaldehyde, which produced an artifactual lowering of quantities of amino acids (data not shown). Severe ATP depletion was probably prevented during these treatments by the greatly increased rate of glycolysis reported to occur with some metabolic inhibitors such as rotenone (Kauppinen and Nicholls, 1986).

\section{Severe ATP deletion released $E A A S$}

High doses of several metabolic inhibitors released endogenous EAAs as well as preloaded OH-Asp from slices (Fig. 3). Increased supernatant concentrations of Glu with concomitant decreased homogenate concentrations were produced by either uncoupling oxidative phosphorylation with dinitrophenol, blocking clectron transport with azide, or inhibiting glycolysis with iodoacetate (see Lehninger, 1975, for a general description of metabolic inhibitors). The data shown were obtained by treatment of slices with the indicated metabolic inhibitor in combination with lowered oxygenation due to lack of bubbling. Treatment with high doses of iodoacetate decreased intracellular Glu more than could be accounted for by simple release (Fig. $3 C$ ), suggesting that significant catabolism of Glu occurred during severe blockade of glycolysis. This catabolism of Glu was

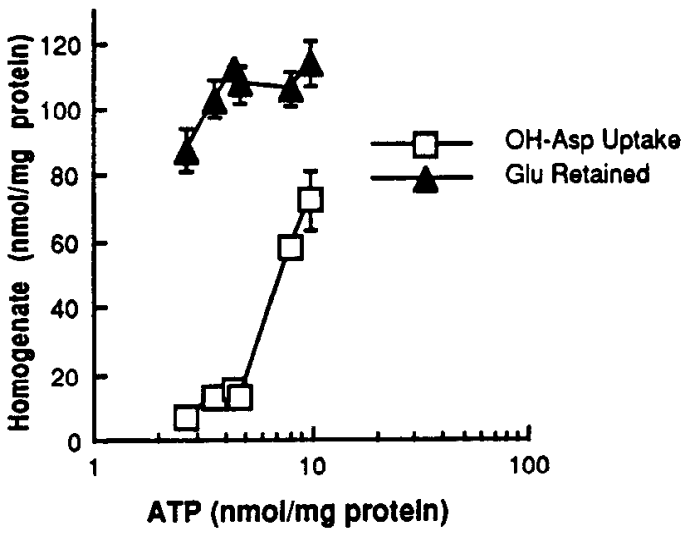

Figure 2. Moderate ATP depletion decreased OH-Asp uptake but did not release endogenous EAAs. Moderate ATP depletion was induced with arsenite, rotenone, or lack of bubbling with $\mathrm{O}_{2}$ (see Table 1 for ATP levels produced by each treatment). EAA uptake was measured by the loading of OH-Asp into slices. Lack of release of EAAs was indicated by the high content of endogenous Glu retained in homogenates. Note the large decreases in uptake of $\mathrm{OH}$-Asp that occurred when ATP was $<5 \mathrm{nmol} / \mathrm{mg}$ protein while endogenous Glu was largely retained in slices. Each point represents the mean of at least four samples after $1 \mathrm{hr}$ treatment; error bars indicate SEM.

accompanied by increased Asp (Fig. 4A) that may represent a conversion of Glu to Asp (Englesen and Fonnum, 1983; Sandburg et al., 1986) with increased release of both Glu and Asp (Fig. 4B).

The release of Glu induced by different toxins (Fig. 5) was highly dependent on ATP content $\left(R^{2}=0.96\right.$ for an exponential curve fit). Different methods of ATP depletion were compared on the basis of percentage maximal release to compensate for Glu and Asp metabolism that occurred during iodoacetate treatment.

\section{Both decreased uptake and increased release of EAAs were consistent with altered cotransporter activity}

It has been hypothesized, based on studies of synaptosomes, that ATP depletion could lead to release of EAAs by reversal of Na-EAA cotransporters. The results of several experiments were consistent with this hypothesis.

First, the effects of exogenous transportable EAA analogs on release were consistent with reversal of cotransporters. Uptake of EAA analogs by cotransporters will increase release of endogenous EAAs by the cotransporters, a process called heteroex-

Table 1. Treatments producing moderate ATP depletion

\begin{tabular}{lll} 
Treatment & ATP $^{a}$ & ATP/ADP \\
\hline Control bubbled $^{\prime}$ & $9.2 \pm 0.69$ & $7.0 \pm 0.5$ \\
Not bubbled & $4.8 \pm 0.54^{*}$ & $5.7 \pm 0.4$ \\
Not bubbled and treated with & & \\
$\quad$ Arsenite $(5 \mathrm{mM})$ & $4.1 \pm 0.47^{*}$ & $2.7 \pm 0.3$ \\
$\quad$ Rotenone $(10 \mu \mathrm{M})$ & $3.4 \pm 0.59^{* \dagger}$ & $2.8 \pm 0.4$ \\
EGTA $(1 \mathrm{mM})$ & $2.4 \pm 0.17^{* \dagger}$ & $3.7 \pm 0.4$
\end{tabular}

${ }^{a}$ Mean ATP content ( $\mathrm{nmol} / \mathrm{mg}$ protein) of at least eight slices $\pm \mathrm{SEM}$

"Continuous bubbling with $95 \% \mathrm{O}_{2}, 5 \% \mathrm{CO}_{2}$.

' Incubation under room air with $5 \% \mathrm{CO}_{2}$.

* Different from control bubbled, $p \leq 0.05$ by $\ell$ test.

$\dagger$ Different from not bubbled, $p \leq 0.05$ by $t$ test. 
A

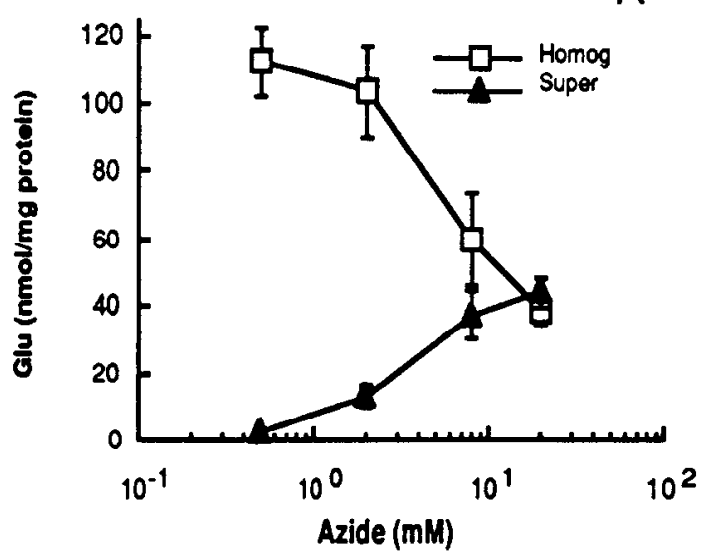

B
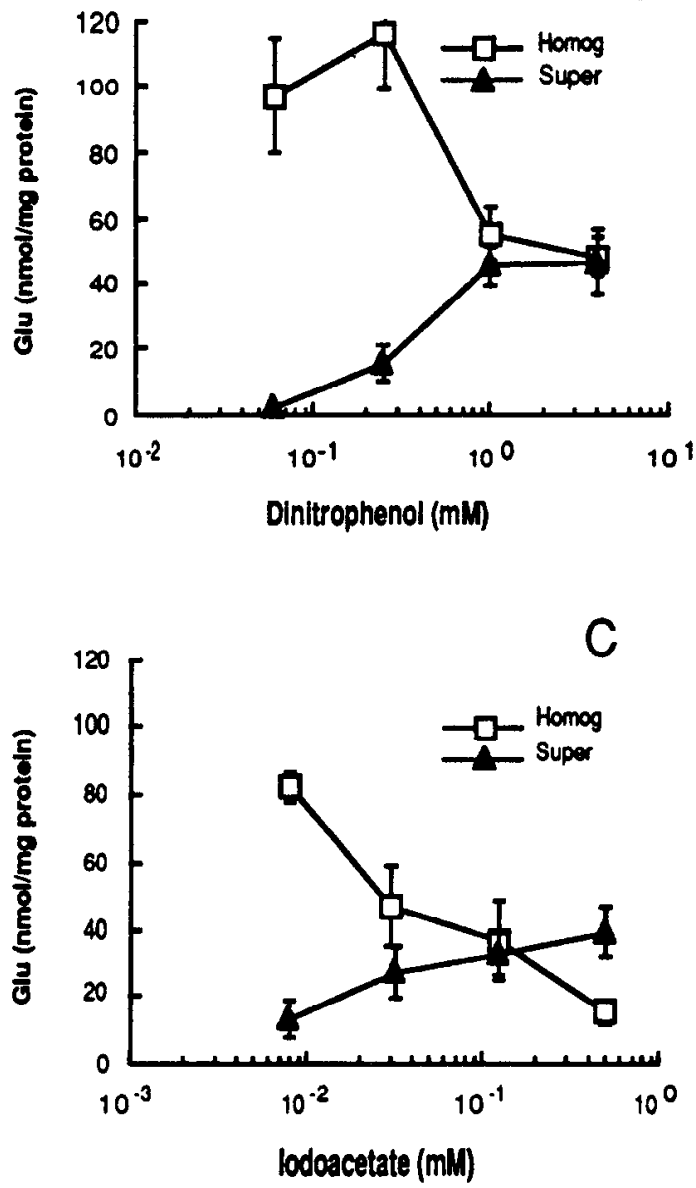

Figure 3. Release of Glu by metabolic inhibitors. A, Blockade of electron transport with sodium azidc released Glu into supernatants with concomitant decreased Glu retention in homogenates. $B$, Uncoupling oxidative phosphorylation with 2,4-dinitrophenol increased Glu in supernatants with concomitant decreased Glu in homogenates. $C$, Blockade of glycolysis with iodoacetate increased Glu in supernatants. However, the reduction in homogenate Glu was greater than release into supernatants, suggesting catabolism of Glu occurred. Homog, Glu in slice homogenates; Super, Glu in slice supernatants. Each point indicates the mean of four replicates after $1 \mathrm{hr}$ incubation with the indicated dose of toxin; error bars represent SEM.
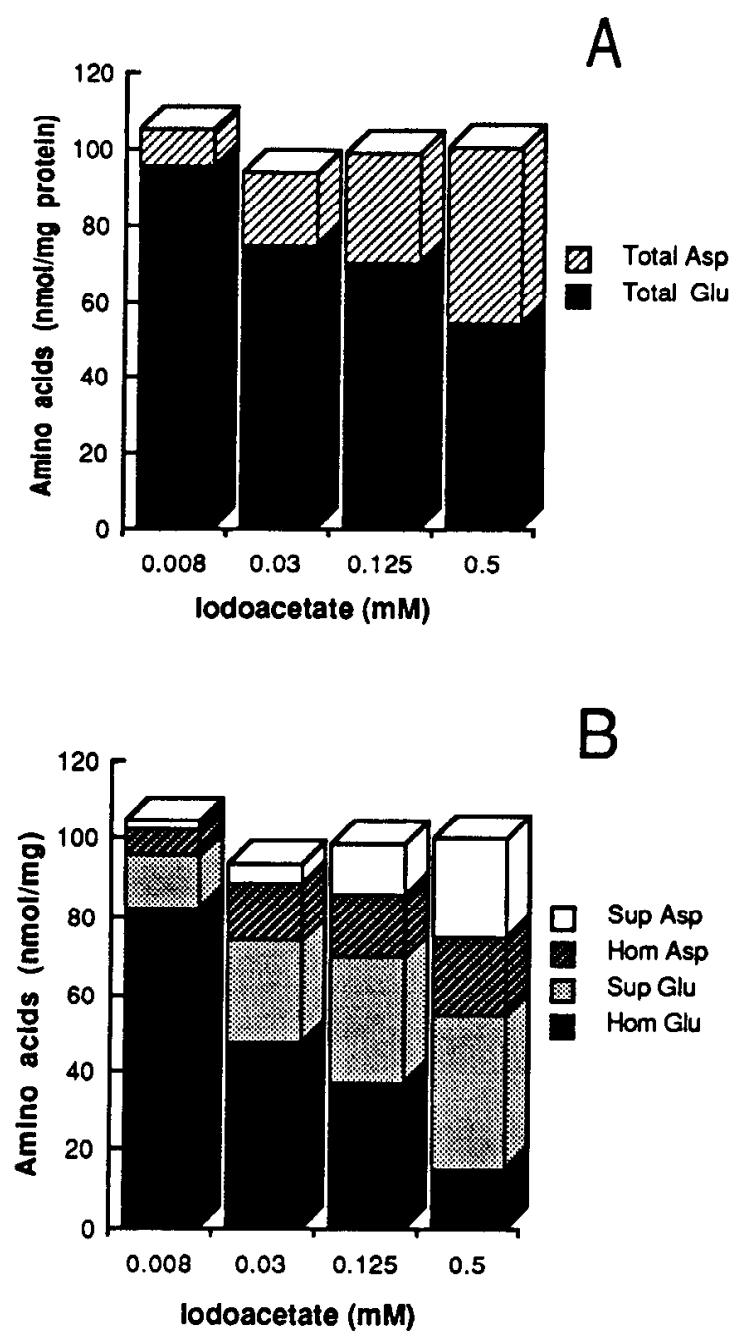

Figure 4. Blockade of glycolysis with iodoacetate resulted in both metabolism and release of Glu. $A$, Total Glu (sum of supernatants and homogenates) was decreased by high doses of iodoacetate while total Asp concomitantly increased, suggesting the conversion of Glu to Asp. $B$, Increasing the dose of iodoacetate increased release of Glu and Asp. Amino acids were determined in four replicate samples at doses indicated in Figure 3C. Sup, supernatants; Hom, homogenates.

change (Wilson and Pastusko, 1986; McMahon et al., 1989). OH-Asp, D-Asp, ADC, and L-trans-pyrrolidine-2,4-dicarboxylic acid (PDC; Tocris Neuramin, Bristol, England) are potent EAA uptake inhibitors (Bridges et al., 1991; Flctcher et al., 1991). When large amounts of these analogs were preloaded into cells their effect was to increase the intracellular concentration of transportable molecules, leading to increased release of EAAs during ATP depletion. Figure $6 A$ shows that increased total intracellular transportable amino acids due to preloading with $\mathrm{OH}-\mathrm{Asp}$ led to increased release of total transportable amino acids (Asp, Glu, and OH-Asp) during ATP depletion. The amounts of Glu and Asp released were highly correlated with each other regardless of which transportable amino acid was loaded into slices (Fig. $6 \mathrm{~B}$ ), consistent with the hypothesis that release of these transportable amino acids was due primarily to reversal of cotransporters. Different methods of ATP depletion induced a similar release of transportable amino acids. Increased supernatant contents of Glu, OH-Asp, and Asp were all highly correlated $\left(R^{2}>0.78\right)$ when release was induced by azide or 


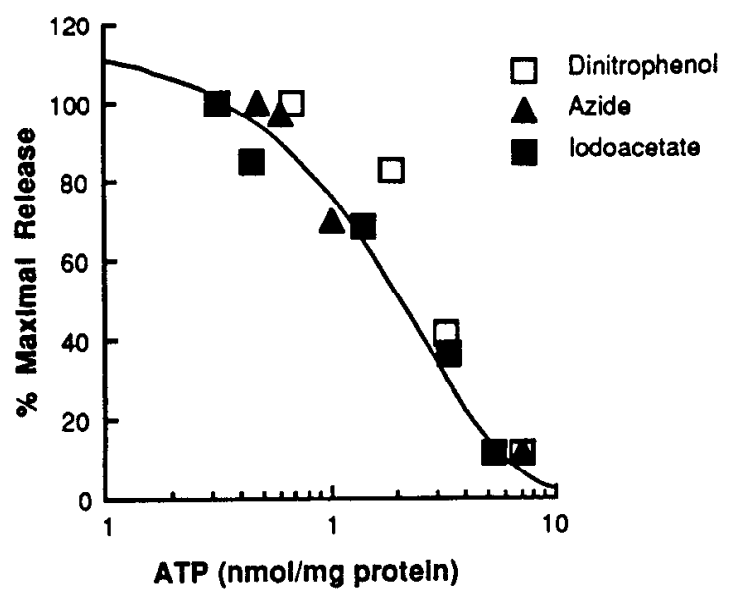

Figure 5. A similar release of Glu was induced by different methods of ATP depletion. $R^{2}$ for the illustrated exponential fit is 0.96 . Doses of inhibitors are those indicated in Figure 3. Each point represents the mean of eight replicates. SEM were generally less than $10 \%$, with a maximal SEM of $20 \%$.

dinitrophenol (Fig. 7). Increases of supernatant Glu and Asp induced by iodoacetate were compared separately due to the changes in content of Glu and Asp induced by iodoacetate (Fig. $4 A$ ).

The effects of administration of EAA uptake inhibitors during ATP depletion were complex. Treatment with the transportable EAA analog PDC during dinitrophenol-induced ATP depletion resulted in increased release of EAAs (Fig. $8 A$ ), consistent with heteroexchange of EAAs with PDC. Trcatment with nontransportable EAA uptake inhibitors during severe ATP depletion would be expected to block reversal of cotransporters and prevent EAA release. Surprisingly, two nontransportable EAA uptake inhibitors, dihydrokainate and arachidonic acid, were unable to prevent accumulations of [EAAs] $]_{e}$ during severe ATP depletion (Fig. $8 B$ ), possibly due in part to the low efficacy of dihydrokainate in some cell types (Barbour et al., 1991).

In contrast to release of EAAs, release of the nonexcitatory amino acids asparagine and glutamine was not dependent on ATP depletion (Fig. 9). The lack of increased release of nonEAAs during ATP depletion suggests there was not a general increase in membrane permeability that would allow all amino acids to escape. Although a large release of nonexcitatory amino acids was obtained without ATP depletion, the retention of 10$20 \%$ of these amino acids in the slices suggests cells were still able to maintain large membrane gradients for these amino acids.

A second way in which release was consistent with reversal of Na-EAA cotransporters is that neither the release of endogenous EAAs nor OH-Asp could be significantly inhibited by chelation of extracellular $\mathrm{Ca}^{2+}$ with EGTA (Fig. 10A). Inhibition of $\mathrm{Na} / \mathrm{K}$-ATPases has been hypothesized to reverse $\mathrm{Na}-\mathrm{EAA}$ cotransporters by decreasing $\mathrm{Na}^{+}$gradients used to power uptake of EAAs. If so, decreasing plasmalemmal $\mathrm{Na}^{+}$gradients should result in release of EAAs similar to that produced by ATP depletion. Decreasing $\mathrm{Na}^{+}$gradients with either veratridine or ouabain produced a release of EAAs that was not reduced by $\mathrm{Ca}^{2+}$ chelation with EGTA (Fig. 10B), in a manner similar to the $\mathrm{Ca}^{2+}$-independent release produced by ATP depletion.

A final way in which release was consistent with reversal of $\mathrm{Na}$-EAA cotransporters is the potentiation of the effects of ATP
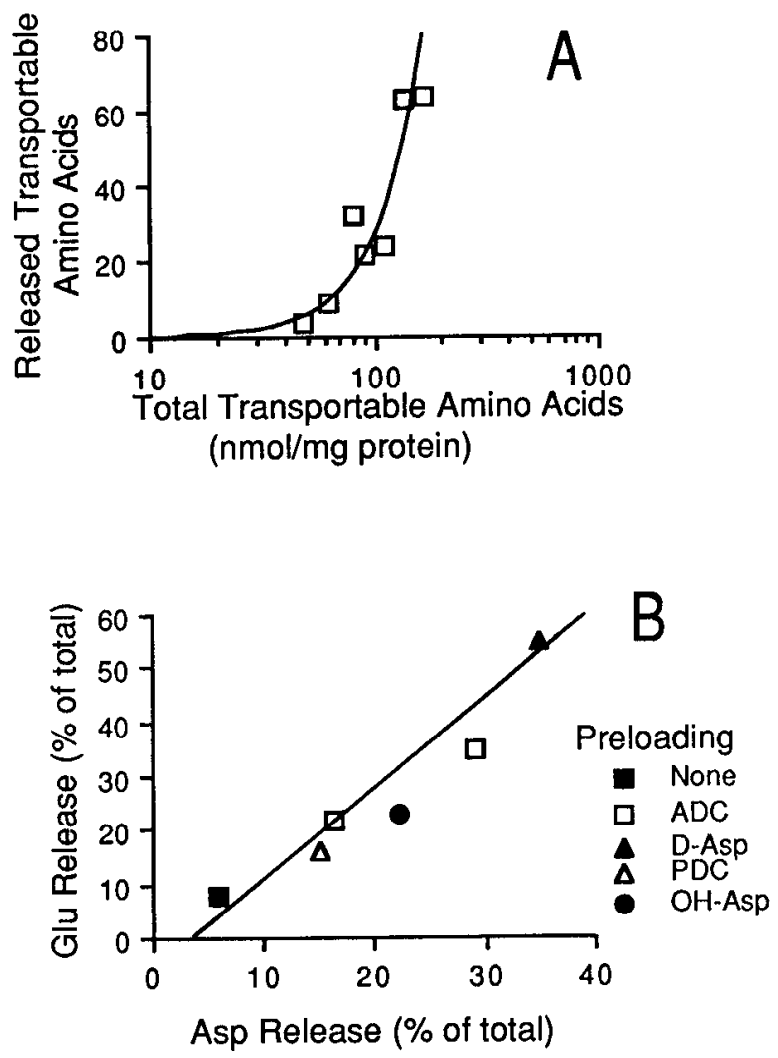

Figure 6. Transportable uptake inhibitors increase EAA release by heteroexchange. $A$, Preloading slices with $\mathrm{OH}$-Asp increased total dinitrophenol-induced release of $\mathrm{OH}-\mathrm{Asp}$, Asp, and Glu into supernatants. Total transportable amino acids represents the sum of OH-Asp, Asp, and Glu. $R^{2}=0.87$ for a logarithmic fit. $\mathrm{OH}$-Asp was loaded at 6,24 , 100 , and $400 \mu \mathrm{M}$ for $1 \mathrm{hr}$ at $37^{\circ} \mathrm{C}$ with bubbling in $95 \% \mathrm{O}_{2}, 5 \% \mathrm{CO}_{2}$. $B$, Increases in the release of both Glu and Asp induced by different analogs were highly correlated. $R^{2}=0.9$. Each point represents the mean of four replicate slices. $A D C, 1$-aminocyclobutane-trans-1,3-dicarboxylic acid; $P D C$, L-trans-pyrrolidine-2,4-dicarboxylic acid. EAA analogs were loaded at $200 \mu \mathrm{M}$ for $1 \mathrm{hr}$ at $37^{\circ} \mathrm{C}$ with bubbling in $95 \% \mathrm{O}_{2}, 5 \%$ $\mathrm{CO}_{2}$.

depletion by ouabain. If the ATP depletion-induced release of Glu and OH-Asp is due to inhibition of $\mathrm{Na} / \mathrm{K}$-ATPases, then the selective inhibitor of $\mathrm{Na} / \mathrm{K}$-ATPases, ouabain, should potentiate the effects of metabolic inhibitors. Treatment of slices with a combination of low doses of ouabain and metabolic inhibitors increased release in a highly synergistic manner, suggesting their mechanisms were not independent (Fig. 11A). Moreover, if ATP depletion-induced release was the result of inhibition of $\mathrm{Na} / \mathrm{K}$-ATPases, then maximal inhibition of $\mathrm{Na}$ / K-ATPases with ouabain should not be potentiated by ATP depletion. The release of Glu and OH-Asp produced by a high dose of ouabain was not significantly increased by azide or iodoacetate (Fig. $11 B$ ), again consistent with the hypothesis that ATP depletion releascd EAAs by inhibition of $\mathrm{Na} / \mathrm{K}-\mathrm{ATPases}$.

\section{Sites of release during ATP depletion}

To examine possible sites of release during ATP depletion, Glu was immunocytochemically localized in control and ATP-depleted slices. In agreement with previous immunocytochemical studies (Storm-Mathisen et al., 1986; Ottersen et al., 1990), much of the Glu-like immunoreactivity (GLIR) found in control slices allowed to recover their energy charge before fixation, was 

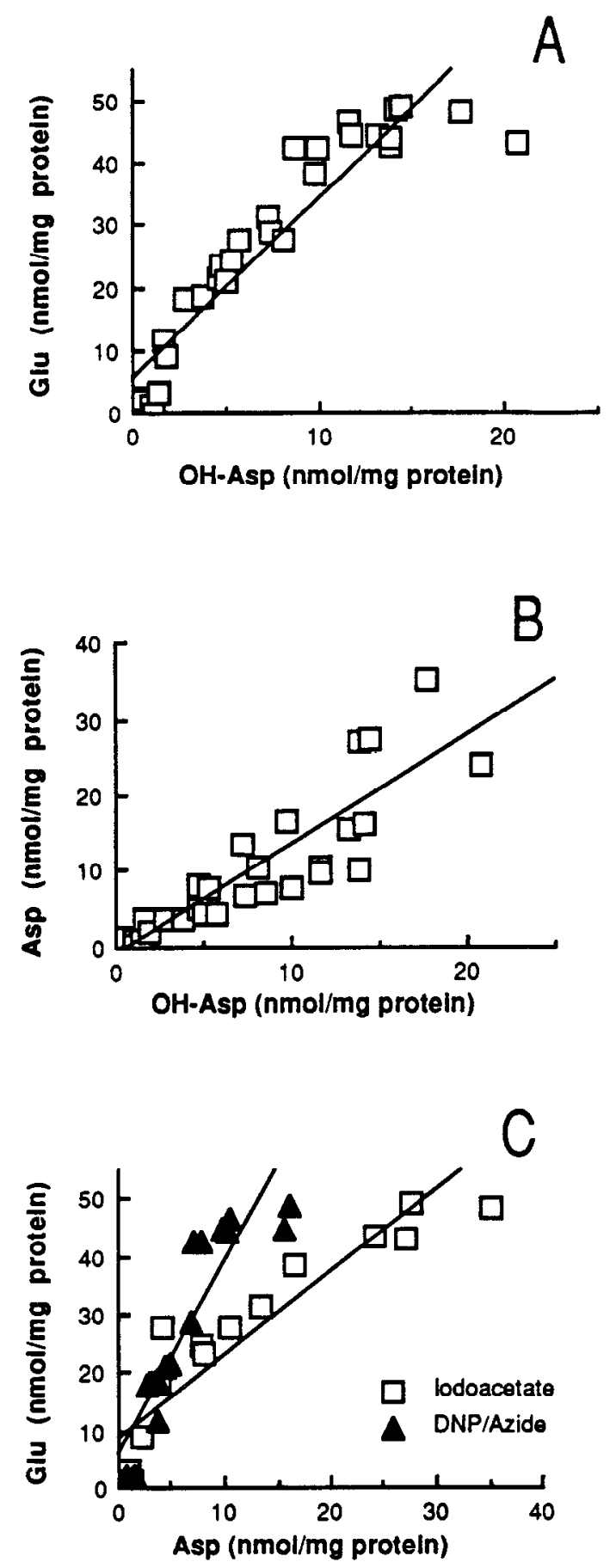

Figure 7. Effects of different toxins on Glu and OH-Asp release. $A$, Comparison of toxin-induced release of Glu and $\mathrm{OH}-$ Asp. Each point indicates release induced by treatment with either azide, dinitrophenol, or iodoacetate. $R^{2}=0.86 . B$, Comparison of toxin-induced release of Asp and $\mathrm{OH}-$ Asp. Each point indicates release induced by treatment with either azide, dinitrophenol, or iodoacetate. $R^{2}=0.78$. $C$, Comparisons of toxin-induced release of Glu and Asp. Iodoacetate induced an apparent conversion of Glu to Asp, requiring separation of iodoacetate-induced release from release induced with azide and dinitrophenol $(D N P) . R^{2}=0.81$ for iodoacetate-induced release and $R^{2}=0.86$ for azide- or dinitrophenol-induced release. Each point represents the mean of four replicates.
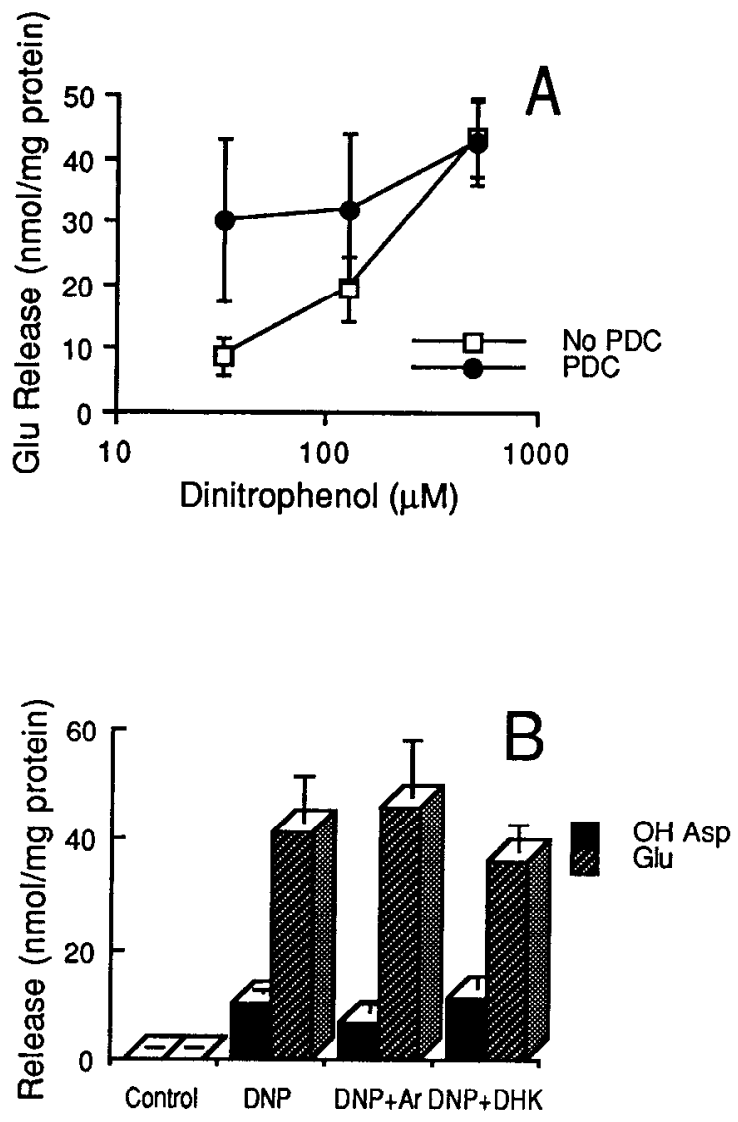

Figure 8. Effects of uptake inhibitors on dinitrophenol-induced release of EAAs. $A$, Effects of the transportable EAA uptake inhibitor PDC on supernatant Glu and Asp. Cotreatment of slices with dinitrophenol and PDC $(100 \mu \mathrm{M})$ increased release of both Glu and Asp by heteroexchange. Each point represents the mean of four replicate slices; error bars represent SEM. $B$, Effects of nontransportable EAA uptake inhibitors on dinitrophenol-induced release. Neither dihydrokainate (1 mM) nor arachidonic acid $(100 \mu \mathrm{M})$ was able to alter significantly the supernatant concentrations of EAAs produced by dinitrophenol $(250 \mu \mathrm{M})$. Each bar represents the mean of three replicate slices; error bars represent SEM. $D N P$, dinitrophenol; $A r$, arachidonic acid; $D H K$, dihydrokainate.

in punctate structures with morphology consistent with axonal terminals (Figs. 12A, 13A). However, if slices were immediately fixed after slicing, large amounts of GLIR were found in neuronal perikarya and dendrites (Fig. 14), similar to the distribution seen in perfusion-fixed tissue (Ottersen and Storm-Mathisen, 1984). The amount of GLIR retained in CA1 pyramidal cell bodies and dendrites after incubation was somewhat variable from rat to rat. Usually perikarya of neurons farthest from the cut edge of the slice retained the most GLIR. Glu content of slices, measured by HPLC, did not change over the first hour while the apparent redistribution of GLIR from neuronal perikarya and dendrites to terminals occurred.

During severe ATP depletion, which released from one-third to two-thirds of the total Glu in the slices (Fig. 3), GLIR was decreased in terminal-like structures (Fig. $12 B-D, 13 C-E$ ). In contrast to the decreased GLIR in terminals, GLIR was increased in some cells with glial-like morphology (Fig. 13). Also in contrast to terminals, GLIR in pyramidal cell perikarya was not greatly decreased during severe ATP depletion (Fig. 12B,C). After moderate ATP depletion, which did not release substantial proportions of Glu from slices (Fig. 2), distribution of GLIR was not obviously different from control slices (Fig. 13B). The 

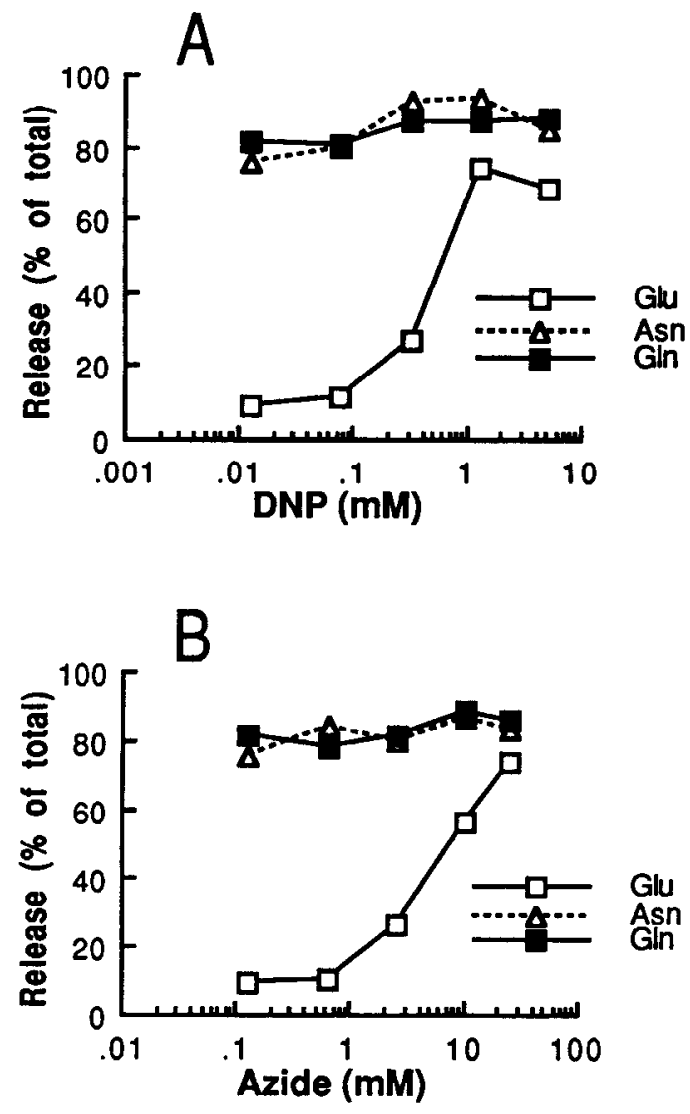

Figure 9. ATP depletion does not affect release of nontransmitter amino acids. $A$, Treatment of slices with dinitrophenol $(D N P)$ did not significantly increase release of glutamine or asparagine $(p>0.2$ by ANOVA). $B$, Treatment of slices with azide did not significantly increase release of glutamine or asparagine ( $p>0.2$ by ANOVA). Each point represents the mean of four replicate slices.

marked decreases of GLIR in terminal-like structures during severe ATP depletion and less marked decrease in other structures suggest most of the Glu release occurred from terminals.

The relatively greater loss of GLIR from terminal-like structures was confirmed by measuring the mean densities of immunostaining in strata containing high proportions of terminals or cell bodies. As seen in Figure 15A, treatments that released about $40 \%$ (azide) or $70 \%$ (dinitrophenol) of the Glu from slices (Fig. 9) resulted in significantly decreased mean staining density of the slices. Analysis of different strata revealed a strong interaction between treatment and strata $(p<0.001$ by ANOVA). When analyzed by multiple comparison tests, the predominant decreases of GLIR were seen in terminal-rich layers (Fig. 15B), although a significant loss of GLIR was also seen in the granule cell layer during very severe ATP depletion (Fig. 15C).

Treatments that decreased $\mathrm{Na}^{+}$and $\mathrm{K}^{+}$gradients produced redistributions of Glu similar to those seen during ATP depletion. Treatment of slices for $1 \mathrm{hr}$ with either $60 \mathrm{~mm} \mathrm{~K} \mathrm{~K}^{+}$(Fig. $16 A$ ), the $\mathrm{Na}^{+}$channel opener veratridine (Fig. $16 C$ ), or the $\mathrm{Na}$ / K-ATPase inhibitor ouabain (Fig. 16B) produced changes in GLIR distribution similar to those produced by ATP depletion, although increases in glial cell GLIR were even more pronounced than those seen with ATP depletion. Redistribution induced by both ATP depletion and reducing $\mathrm{Na}^{+}$gradients included loss of GLIR from terminal-like structures, increased
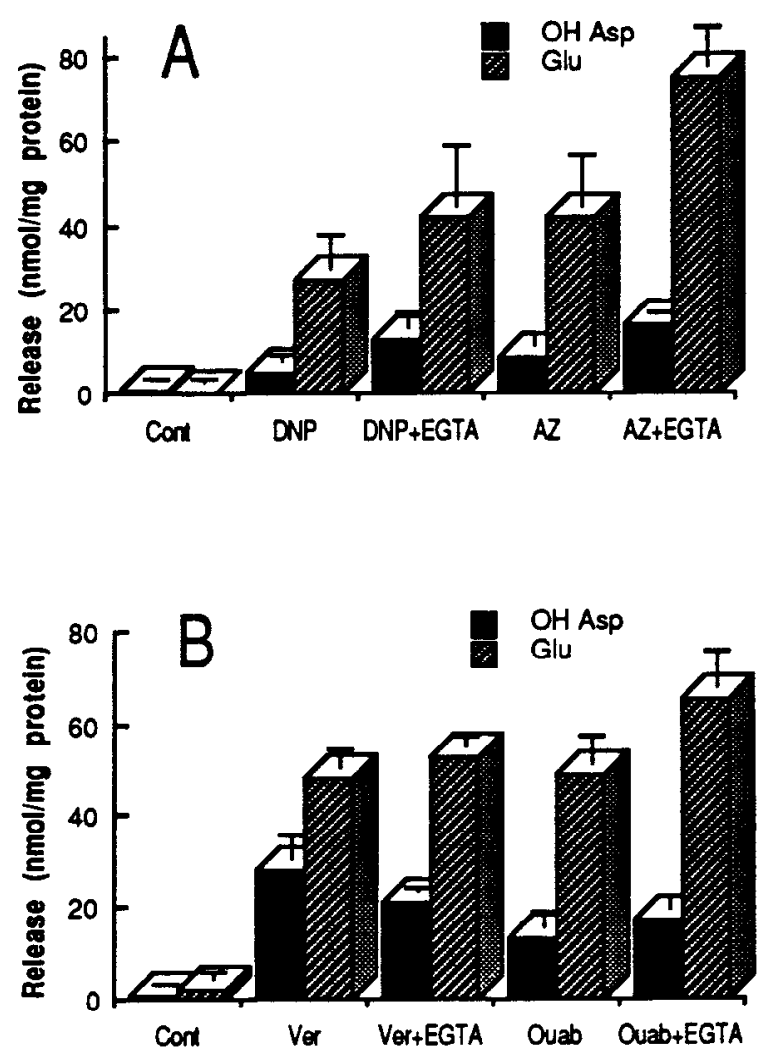

Figure 10. EGTA does not reduce the relcase of EAAs induced by ATP depletion or decreased $\mathrm{Na}^{+}$gradients. $A$, Chelation of extracellular $\mathrm{Ca}^{2+}$ with EGTA (1 mM) was unable to decrease the release of EAAs induced by treatment with azide $(A z ; 5 \mathrm{~mm})$ or dinitrophenol (DNP; $0.5 \mathrm{~mm}) . B$, Treatment of slices with ouabain $(\mathrm{Ouab} ; 100 \mu \mathrm{M})$ or veratridine (Ver; $50 \mu \mathrm{M})$ resulted in release that was also not reduced by chelation of extracellular $\mathrm{Ca}^{2+}$ with EGTA $(1 \mathrm{mM})$. Error bars represent SEM.

GLIR in cells with glial-like morphology, and retention of GLIR in pyramidal cell perikarya.

\section{Discussion}

Increased $[\mathrm{EAAs}]_{e}$ are believed to mediate many neuronal insults. Although reversal of glial cotransporters induced by decreased $\mathrm{Na}^{+}$and $\mathrm{K}^{+}$gradients has been confirmed (Szatkowski et al., 1990), little experimental evidence is available evaluating the role of ATP depletion in altering the activity of cotransporters. We therefore examined whether the increased [EAAs] occurring during metabolic insults were consistent with increased release and/or decreased uptake of EAAs mediated by a common mechanism such as ATP depletion.

One mechanism by which metabolic insults could release EAAs was selected for testing by several methods. This hypothesis proposes that increased [EAAs] $]_{e}$ are due to reversal of Na-EAA cotransporters as a result of decreased $\mathrm{Na}^{+}$and $\mathrm{K}^{+}$gradients produced by inhibition of $\mathrm{Na} / \mathrm{K}$-ATPases (Dagani and Erecinska, 1987). EAAs are normally transported into neurons and glia against a large concentration gradient by Na-EAA cotransporters, thereby maintaining low extracellular concentrations of Glu in the CNS (for discussion, see Erecinska, 1987). The uptake of an amino acid is powered by cotransport of two $\mathrm{Na}^{+}$into the cell and the release of a $\mathrm{K}^{+}$and an alkalinizing anion into the extracellular fluid, resulting in a net influx of positive charge (Bouvier et al., 1992). Na-EAA cotransporters are reversible 

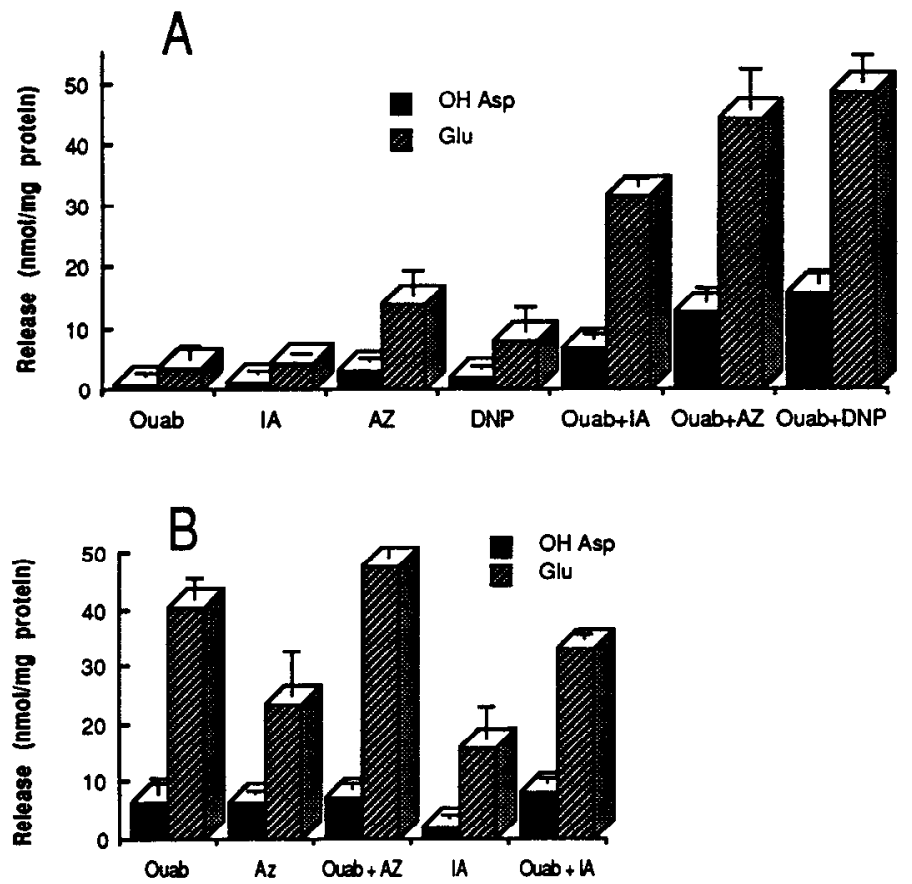

Figure 11. Interaction of ouabain and ATP depletion. $A$, A low dose of ouabain $(O u a b ; 1 \mu \mathrm{M})$ acted synergistically with low doses of iodoacetate $(I A ; 8 \mu \mathrm{M})$, azide $(A 7 ; 1 \mathrm{~mm})$, or dinitrophenol $(D N P ; 0.1$ $\mathrm{mm})$ to produce release of EAAs. Note that combined treatments produced more than twice the release of the sum of the individual treatmonts. $B$, Relcase of EA $\Lambda$ s induced by near-maximal doses of ouabain $(500 \mu \mathrm{M})$ was not significantly potentiated ( $p>0.2$ by $t$ test) by a high dose of azide ( $5 \mathrm{~mm}$ ) or iodoacetate $(2 \mathrm{~mm})$. Each column indicates the mean of four replicates; error bars represent SEM.

and electrogenic; therefore, decreases of $\mathrm{Na}^{+}$and $\mathrm{K}^{+}$gradients as well as depolarization should first decrease the rate of uptake and eventually, if severe enough, reverse the net direction of EAA transport until a new equilibrium is reached based on the Nernst potentials for the ions and EAAs (Szatkowski et al., 1990; Bouvier et al., 1992). Hypoxia and ischemia increase both intracellular $\mathrm{Na}^{+}$concentrations and extracellular $\mathrm{K}^{+}$concentrations (as reviewed by Hansen, 1985), and should therefore reduce EAA uptake into cells. If these gradients are sufficiently decreased by severe metabolic insults, decreased EAA uptake should be followed by release of EAAs from cytosolic pools into the extracellular fluid by reversal of the cotransporters.

\section{Is ATP depletion a common mediator of metabolic insult-induced [EAAs] increases?}

Studies employing in vivo microdialysis suggest large accumulations of [EAAs] $]_{e}$ occur during CNS insults that deplete ATP such as ischemia (Benveniste et al., 1984; Drejer et al., 1985) and hypoglycemia (Butcher et al., 1987). In slices, severe ATP depletion induced by either inhibition of glycolysis, inhibition of electron transport, or uncoupling of oxidative phosphorylation all led to greatly increased supernatant EAAs with reductions of intracellular EAAs, consistent with an increased release of EAAs. The strong correlation between ATP depletion and release of EAAs is consistent with ATP depletion mediating the bulk of the EAA release produced by these different metabolic insults. However, blockade of glycolysis also led to an apparent conversion of Glu to Asp, suggesting that certain metabolic insults can also lead to significant metabolism of EAAs, thus affecting the quantities of EAAs available for release.

\section{Are increased [EAAs] the result of nonselectively increased membrane permeability, altered cotransporter activity, or increased vesicular release?}

It is unlikely that the majority of the release of EAAs observed during ATP depletion was the result of nonselective increases of membrane permeability for several reasons. First, in contrast to EAAs, release of the non-EAAs glutamine and asparagine did not depend on ATP depletion, suggesting ATP depletion did not produce "leaky" membranes. Second, only about half of the total Glu was released during severe ATP depletion, suggesting membranes could still maintain large EAA gradients. The large amounts of GLIR remaining in pyramidal cell perikarya of ATPdepleted slices (Fig. 12) also suggest there was no major loss of plasmalemmal integrity.

The bulk of the release of EAAs was consistent with reversal of Na-EAA cotransporters in several ways. First, the amounts of Glu and Asp released were highly correlated with each other and with the release of preloaded transportable EAA analogs. Second, heteroexchange with other transportable amino acids increased the ATP depletion-induced release of EAAs. Bouvier et al. (1992) suggested the extracellular concentration of Glu at equilibrium should depend on the Nernst potential for Glu. Increasing intracellular Glu or preloading large amounts of any transportable amino acid should then increase the release of all transportable amino acids to reach the same final ratio of [EAAs] $]_{e}$ : [EAAs $]_{i}$. Third, release produced by reversing Na-EAA cotransporters through decreasing $\mathrm{Na}^{+}$and $\mathrm{K}^{+}$gradients resembled the release produced by ATP depletion in both $\mathrm{Ca}^{2+}$ insensitivity (Fig. 10), and selective loss of Glu from terminal regions (Fig. 15). Fourth, as discussed in a following section, ATP depletion and ouabain act synergistically to increase EAA release, suggesting both act by decreasing $\mathrm{Na}^{+}$and $\mathrm{K}^{+}$gradients. Finally, inhibition of EAA uptake occurred before release of EAAs. This is consistent with milder ion gradient changes inhibiting cotransporter uptake, followed by reversal of uptake and release of EAAs by more severe changes.

It is unlikely exocytosis from synaptic vesicles contributed substantially to release for several reasons. First, Asp is not loaded into synaptic vesicles, nor is it likely that OH-Asp is

Figure 12. Effects of ATP depletion and $\mathrm{Na}^{+}$influx on GLIR in CAl. $A$, Section of unbubbled slice showing intense staining for Glu in puncta with terminal-like morphology in stratum radiatum $(R)$ and stratum oriens $(O)$. Note staining of some pyramidal cell bodies $($ arrowheads). $B$, Effects of azide $(5 \mathrm{~mm})$ on Glu distribution. Reduced intensity of staining of puncta in stratum radiatum and stratum oriens was evident, with staining retained or increased in pyramidal cell perikarya (arrowheads). C, Effects of dinitrophenol ( $2 \mathrm{~mm})$ on Glu distribution. Note reduced staining of puncta and retention of pyramidal cell staining (arrowheads). D. Effects of increasing $\mathrm{Na}^{+}$influx with veratridine $(50 \mu \mathrm{M})$ on $\mathrm{Glu}$ distribution. Note similarities of Glu redistribution to ATP depletion shown in $B$ and $C$. Increased $\mathrm{Na}^{+}$influx and ATP depletion both decreased intensity of punctal staining in stratum radiatum and stratum oriens with retention of Glu in pyramidal cell perikarya (arrowheads). All parts of the figure have similar orientation and the same magnification. $P$, stratum pyramidale. Scale bar, $50 \mu \mathrm{m}$. 

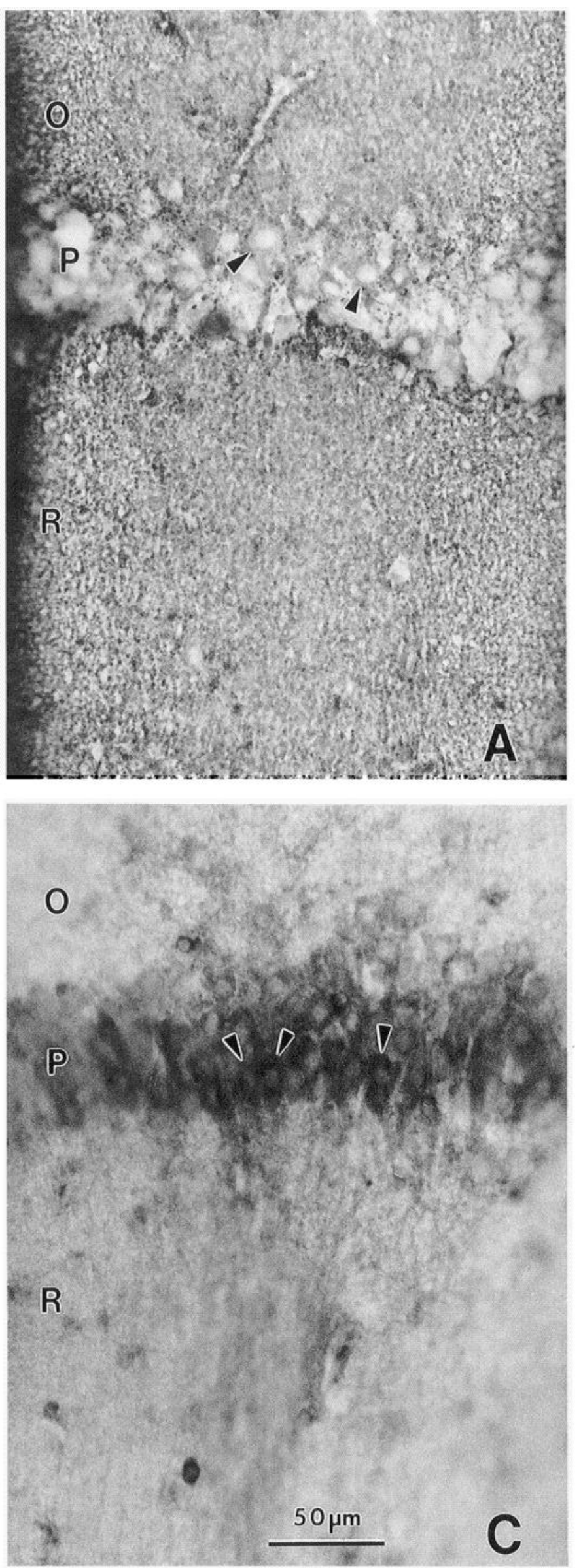

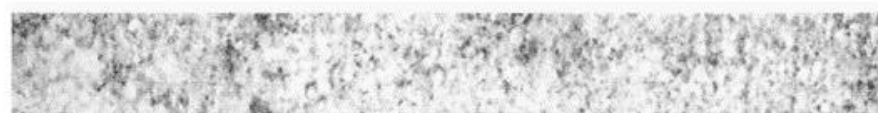
6.

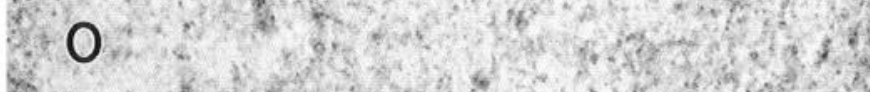

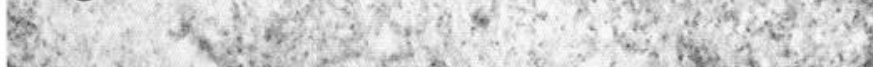

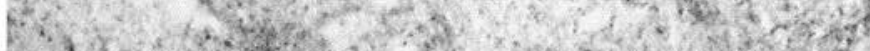

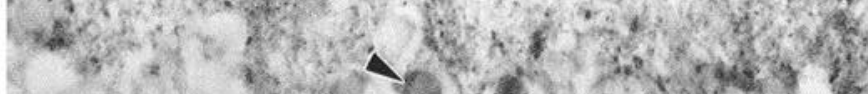

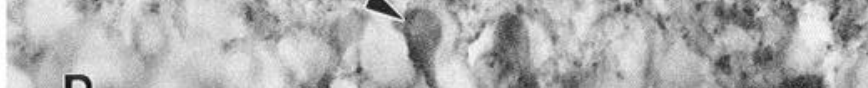

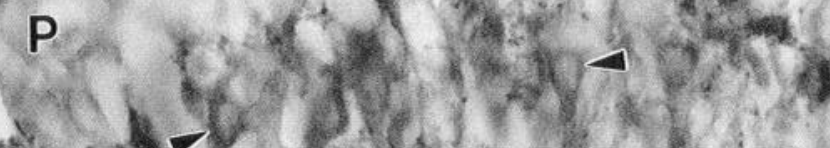

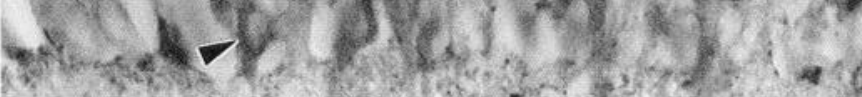

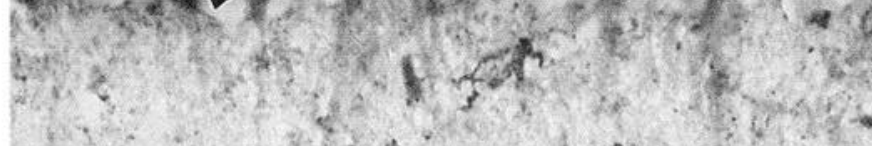

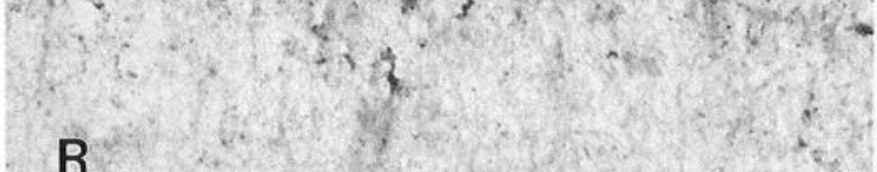

R

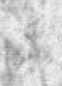

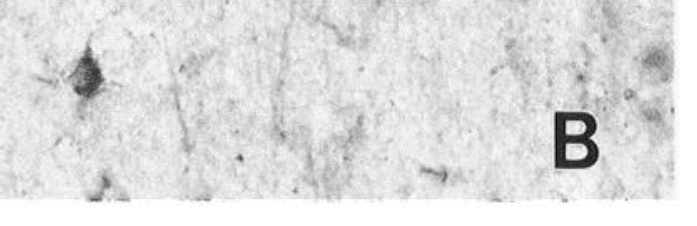
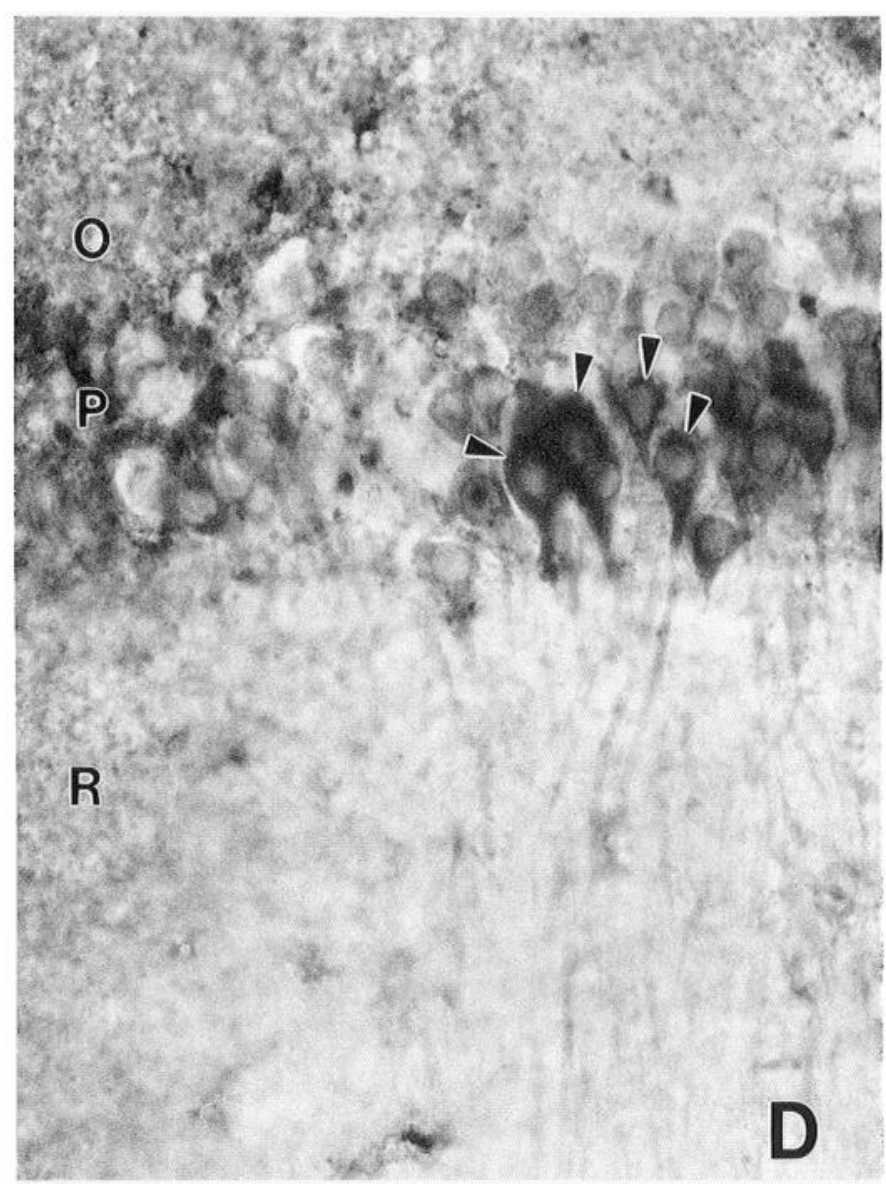

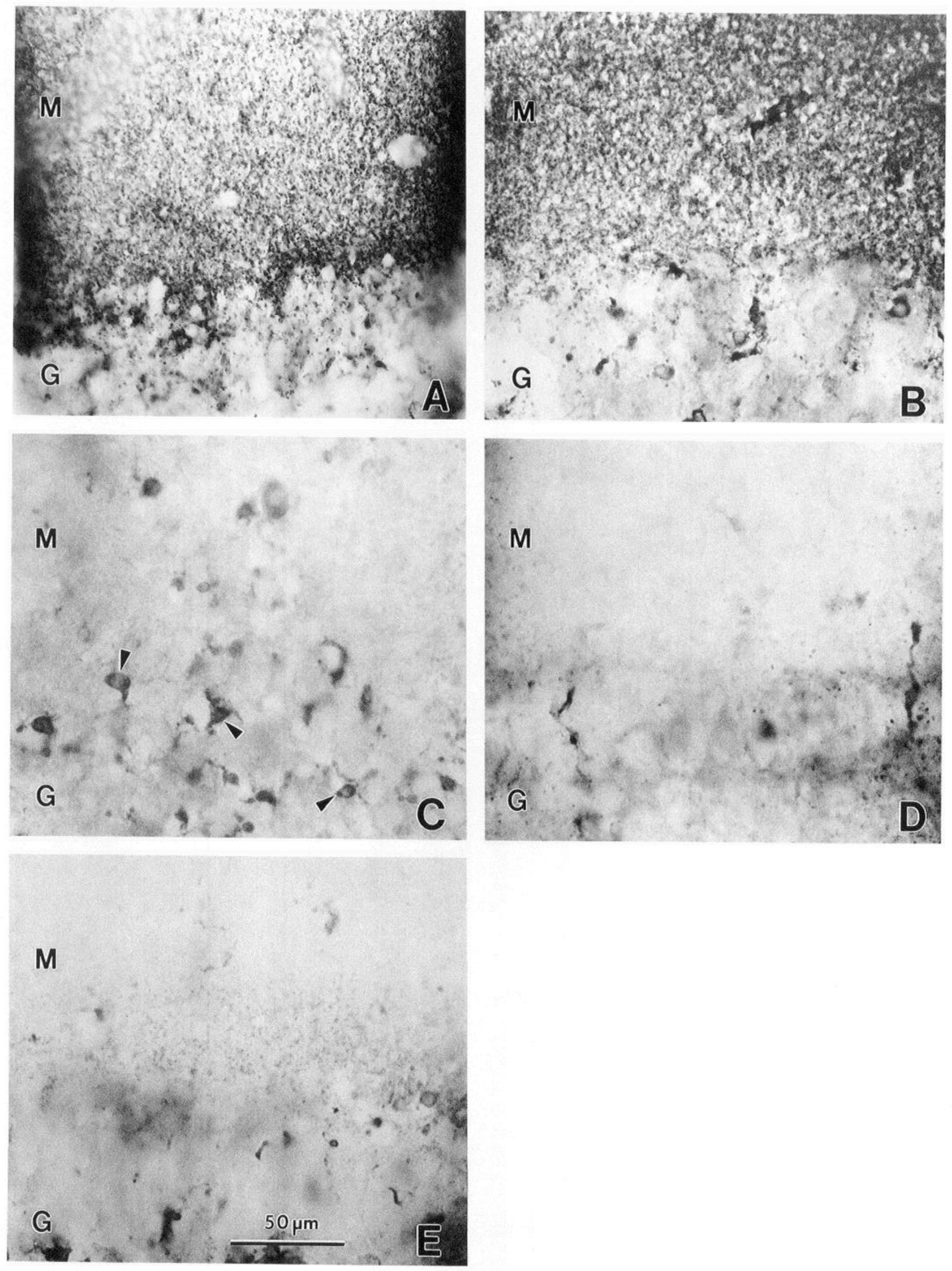
loaded into synaptic vesicles, given the specificity of vesicular loading mechanisms (Naito and Ueda, 1985). Second, the inability of chelation of extracellular $\mathrm{Ca}^{2+}$ with EGTA to block release of EAAs also suggests the release occurred primarily by a nonexocytotic mechanism, consistent with reversal of $\mathrm{Na}-$ EAA cotransporters. Finally, $\mathrm{Ca}^{2+}$-dependent release occurs chiefly during the first 5 min of ischemia (Katayama et al., 1991) or exposure to high concentrations of $\mathrm{K}^{+}$(Kish and Ueda, 1991; reviewed by Adam-Visi, 1992), suggesting the release obtained over $1 \mathrm{hr}$ of ATP depletion has only a small component due to vesicular release.

Are the increases of [EAAs] $]_{\mathrm{e}}$ due to both decreased uptake and increased release of $E A A$ s, and does either means of increasing $[E A A s]_{\mathrm{e}}$ predominate during milder insults?

Moderate ATP depletion, such as that produced by lack of bubbling of slices with oxygen, reduced uptake of FAAs to $10-20 \%$ of bubbled slices with little release of endogenous EAAs. These results are similar to those of Pastuszko et al. (1982), who found that anoxic incubations of synaptosomes decreased uptake without increasing release of GABA or other transmitters. The mild ATP depletion produced early in hypoxia/ischemia may produce an inhibition of uptake of EAAs from the synaptic cleft, contributing to ncuronal depolarization and interruption of synaptic transmission that occurs in hypoxic slices (Lipton and Whittingham, 1979, 1982). Increased excitation of cat spinal motor neurons by EAAs occurs when EAA uptake is inhibited with $\mathrm{OH}-\mathrm{Asp}$, suggesting synaptic transmission can be rapidly altered by lack of uptake of EAAs (Johnson et al., 1980). Rosen and Morris (1991) have suggested that a release of EAAs due to partial failure of $\mathrm{Na} / \mathrm{K}$-ATPases may contribute to anoxic depolarization of rat neocortical slices. In addition to any rapid effects on synaptic function, decreased EAA uptake might also contribute to neuronal damage. Neuronal damage consistent with excess EAA stimulation was seen after injection of $\mathrm{OH}$ Asp in rat striatum, suggesting lack of uptake of EAAs released during normal processes may be sufficient to produce excitotoxic neuronal damage (McBean and Roberts, 1985). The prolonged activation of postsynaptic cells by inhibition of EAA uptake may contributc to the ncuronal depolarization seen during hypoxia of the CNS and may contribute to hypoxic/ischemic neuronal damage.

It should be noted that the ATP content of even bubbled slices is only about half that of in vivo CNS tissue. This suggests that even highly oxygenated control slices may already exhibit some differences from normal tissue. However, as discussed by Whittingham et al. (1984), the energy charge of slices approaches that of in vivo tissue (about 0.9 ). These seemingly contradictory results are consistent with a large release of adenosine and other adenylates during the process of making slices, when the energy charge of the slice is lowered to about 0.4 . A similar release of adenosine and accumulation of its metabolites hypoxanthine and inosine has been reported during in vivo ischemia (Hagberg et al., 1987). These adenylates may then be unavailable for reuptake due to dilution or changing rinse solutions even after slices have recovered from the process of slicing. We have observed the release of large amounts of adenosine, hypoxanthine, and inosine into washing media during slice preparation that could result in lowered adenylates after recovery (data not shown).

Are changes in cotransporter activity mediated by inhibition of $\mathrm{Na} / K$-ATPases during ATP depletion?

Much of the ATP generated in the CNS is used to power $\mathrm{Na} /$ $\mathrm{K}$-ATPases that maintain $\mathrm{Na}^{+}$and $\mathrm{K}^{+}$gradients (Erecinska and Dagani, 1990). Na/K-ATPases have a low-affinity binding site for ATP (approximate $K_{\mathrm{m}}=0.2-0.4 \mathrm{~mm}$; Glynn and Karlish, 1975; Robinson, 1982) that may regulate their activities. It has been suggested by Dagani and Erecinska (1987) and Kauppinen et al. (1988) that depletion of ATP during pathologic processes could lead to inhibition of $\mathrm{Na} / \mathrm{K}$-ATPases, resulting in decreased $\mathrm{Na}^{+}$and $\mathrm{K}^{+}$gradients and a reversal of $\mathrm{Na}-\mathrm{EAA}$ cotransporters. The release of Glu from synaptosomes they observed during ATP depletion was consistent with decreases in ion gradients and $\mathrm{Na} / \mathrm{K}-\mathrm{ATPase}$ activity. The dependence of release on ATP concentration is consistent with the hypothesis that reversal of the cotransporters during ATP depletion is due to a single mechanism such as inhibition of the $\mathrm{Na} / \mathrm{K}-\mathrm{ATPases}$.

The release produced by decreasing $\mathrm{Na}^{+}$or $\mathrm{K}^{+}$gradients resembled that produced by ATP depletion. Both produced primarily a $\mathrm{Ca}^{2+}$-insensitive release of EAAs (Fig. 10), and both caused a redistribution of Glu similar to those produced by ouabain and ATP depletion (Fig. 16).

To test more directly whether inhibition of the $\mathrm{Na} / \mathrm{K}-\mathrm{ATP}$ Pase mediates ATP depletion-induced release of EAAs, the effects of ATP depletion on oubain-induced release were examined. Ouabain, a selective inhibitor of $\mathrm{Na} / \mathrm{K}$-ATPases (Sweadner, 1989), may release EAAs by reversing Na-EAA cotransporters as a result of decreased plasma membrane $\mathrm{Na}^{+}$and $\mathrm{K}^{+}$gradients. Ouabain-induced release was similar to ATP depletioninduced release both in $\mathrm{Ca}^{2+}$ insensitivity (Fig. 10B) and in the changes in Glu distribution they produce (Fig. 16). Ouabain does not reduce slice ATP content sufficiently to produce depletion-dependent release of EAAs (data not shown). Treatment of slices with a combination of low doses of ouabain and toxins resulted in highly synergistic release of EAAs (Fig. 11 $A$ ), suggesting the release was not independent. A combination of high doses of ouabain with either azide or iodoacetate produced a release that was not significantly increased above that achieved by ouabain alone (Fig. $11 B$ ). The inability of ATP depletion to increase ouabain-induced release strongly suggests the release of EAAs due to ATP depletion was mediated by inhibition of $\mathrm{Na} / \mathrm{K}-\mathrm{ATPases}$.

\section{Does release of Glu occur selectively from glia, neurons, or subcellular locations such as nerve terminals?}

Immunocytochemical localization of Glu in slices allowed to recover their energy charge suggests large amounts of Glu are found in axonal terminals (Storm-Mathisen et al., 1986). Severe

Figure 13. Effects of ATP depletion on GLIR in the area dentata. $A$, Control section showing intense staining for Glu in terminal-like punctate structures in stratum moleculare $(M)$. Note lack of staining of granule cells in stratum granulosum $(G)$. $B$, Lack of effect of moderate ATP depletion with rotenone on Glu distribution. Note intense staining of puncta in stratum moleculare is retained. $C$, Effects of severe ATP depletion with dinitrophenol ( $2 \mathrm{~mm})$ on Glu distribution. Note reduced intensity of staining of puncta in stratum moleculare. Some intense labeling of glial-like cells is evident (arrowheads). D. Effects of severe ATP depletion with iodoacetate $(2 \mathrm{~mm})$ on Glu distribution. Note reduced intensity of staining of puncta in stratum moleculare. $E$, Effects of severe ATP depletion with azide (5 mM) on Glu distribution. Note reduced intensity of staining of puncta in stratum moleculare. All parts of the figure have similar orientation and the same magnification. Scale bar, $50 \mu \mathrm{m}$. 

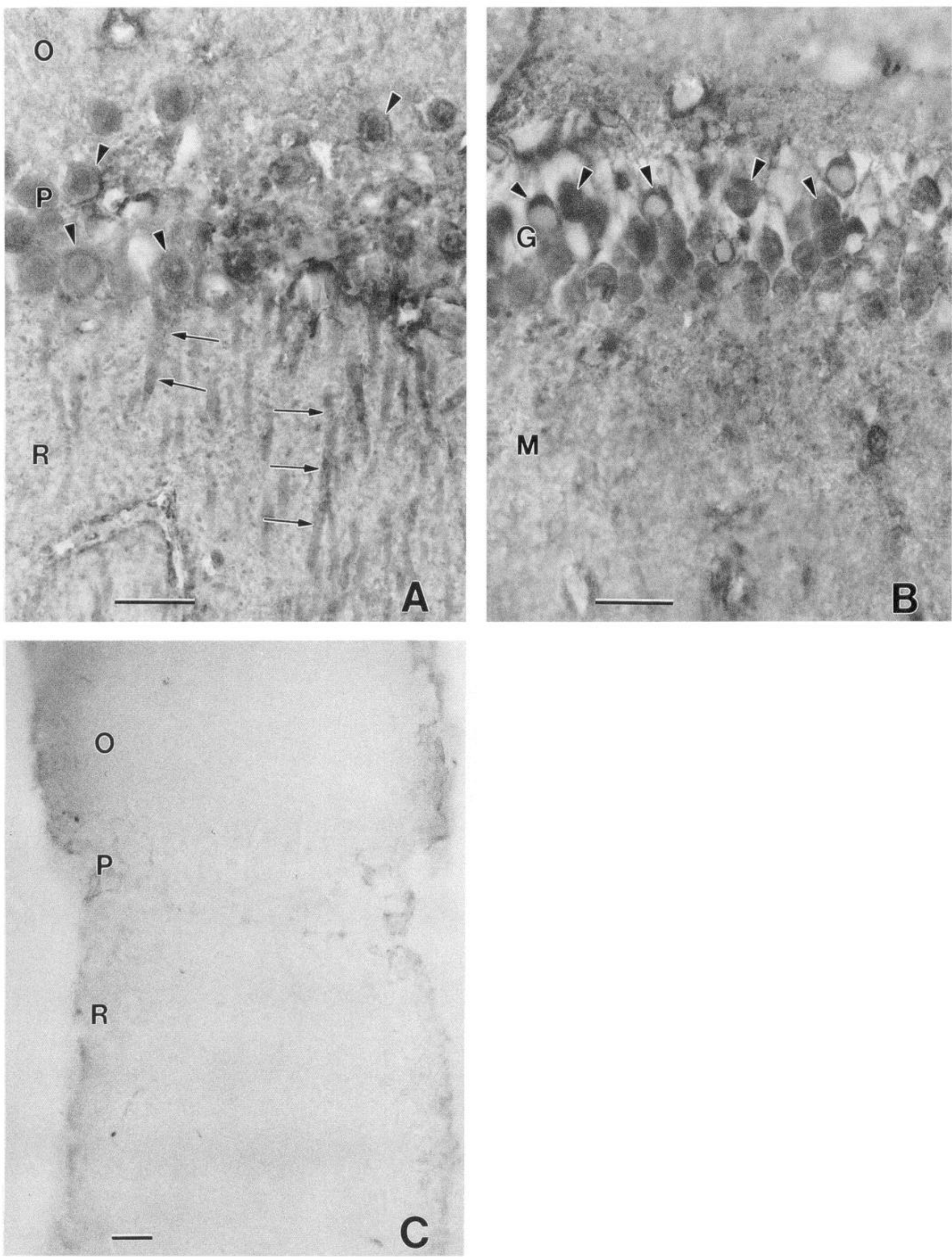
ATP depletion released more than half the Glu in slices (Fig. 9) and decreased GLIR in these terminal-like structures, suggesting release of EAAs occurred primarily from axonal terminals. These results are consistent with reports that deafferentation decreased release of EAAs produced by hypoglycemia (Butcher et al., 1987) and ischemia (Benveniste et al., 1989), suggesting the primary site of release was from terminals. It is unlikely glia contributed greatly to the increased release seen during ATP depletion. In contrast to terminals, cells with gliallike morphology infrequently contained large amounts of GLIR in control slices. ATP depletion increased the number of intensely labeled cells with glial-like morphology, suggesting Glu may accumulate in some glia during ATP depletion, rather than be released. HPLC data indicate severe ATP depletion released large proportions of the Glu in slices. Taken together with immunocytochemical studies suggesting GLIR is decreased primarily from terminals during ATP depletion, these results strongly suggest most of the release during ATP depletion is from terminals. Glu within the cytosolic compartment of these terminals, rather than Glu in synaptic vesicles, is the most likely source of the released Glu since the cytosolic pool is accessible to the Na-EAA cotransporters associated with the plasmalemma. Lack of a major contribution of exocytosis to ATP depletion-induced release is also suggested by the inability of EGTA to decrease release.

Several reasonable mechanisms could account for the differential loss of EAAs from neuronal cell bodies, axonal terminals, and glia. Likely mechanisms include the nonhomogeneous distributions of cotransporters or subunits of $\mathrm{Na} / \mathrm{K}-\mathrm{ATPases}$. Immunocytochemical localization of subunit isoforms in the hippocampus indicated pyramidal cell bodies possess large amounts of the $\alpha 3$ isoform with some $\alpha 1$ labeling, while pyramidal cell dendrites appeared to possess primarily $\alpha 1$. Stratum oriens was highly labeled for $\alpha 2$ and $\alpha 3$, while stratum radiatum was labeled for all three isoforms, suggesting terminals may contain large amounts of the $\alpha 2$ and $\alpha 3$ isoforms (McGrail et al., 1991). The $\alpha 1$ isoform has a threefold lower $K_{\mathrm{m}}$ for $\mathrm{Na}^{+}$and a slightly lower $K_{\mathrm{m}}$ for ATP (Jewell and Lingrel, 1991). Differences in the $K_{\mathrm{m}}$ of these isoforms for both $\mathrm{Na}^{+}$and ATP might result in different $\mathrm{Na}^{+}$and $\mathrm{K}^{+}$gradients, producing regional differences in neuronal uptake and release of EAAs by cotransporters. The higher $K_{\mathrm{m}}$ for $\mathrm{Na}^{+}$of $\alpha 3$ pumps of neurons suggests higher levels of intracellular $\mathrm{Na}^{+}$may accumulate in neurons or within regions of the neurons such as axonal terminals, perhaps leading to easier reversal of cotransporters in these regions during ATP depletion. It is also likely that cotransporters are not homogeneously distributed throughout neurons and glia. Wiklund et al. (1984) reported that $\mathrm{D}$-Asp is selectively taken up by axonal terminals and glia in the cerebellum and not by neuronal perikarya. This indication that neuronal EAA uptake sites occurs primarily on terminals is consistent with our findings that release of EAAs due to reversal of the cotransporters may also occur principally at terminals.

Another mechanism that could account for a relatively greater release of Glu from terminals concerns the smaller size of ter-
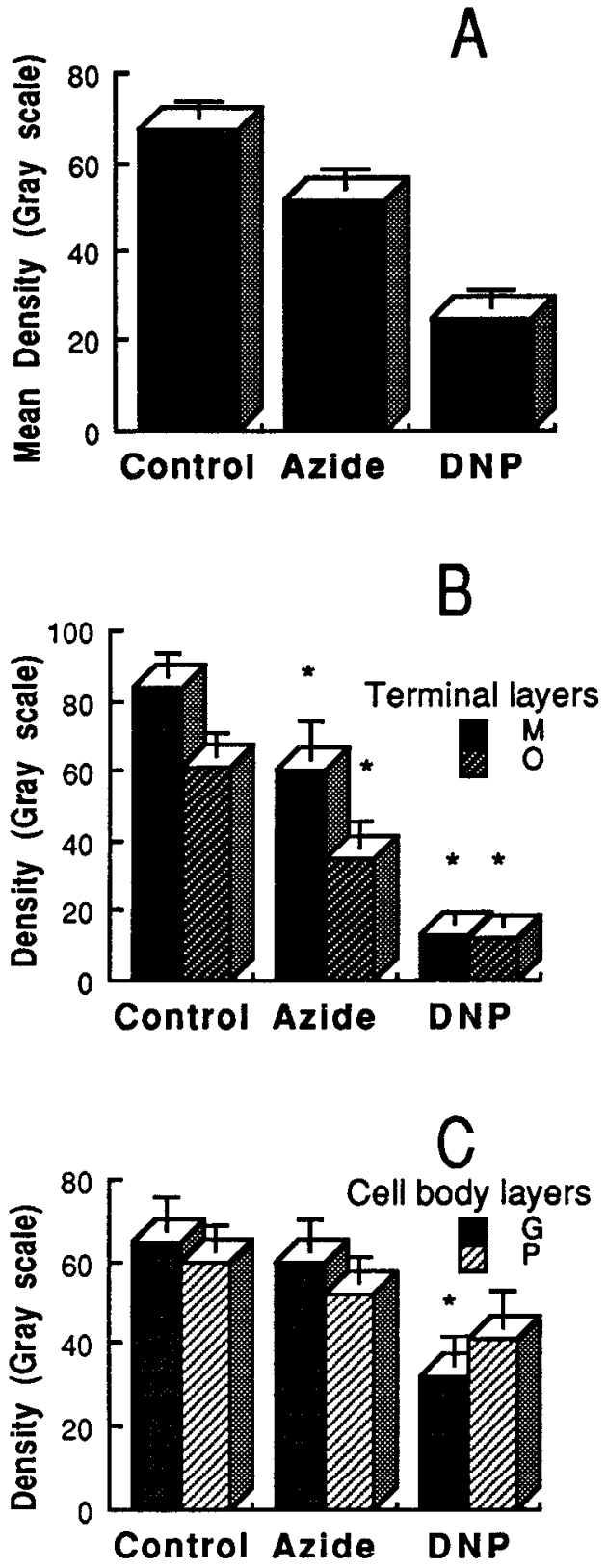

Figure 15. The effects of ATP depletion on density of immunocytochemical staining for Glu. $A$, Metabolic inhibitors decreased the mean of the staining densities of four layers of hippocampal slices. Glu depletions of about $40 \%$ ( $5 \mathrm{~mm}$ azide) or $70 \%$ ( $1 \mathrm{~mm}$ dinitrophenol) measured by HPLC produced significant decreases in staining intensity ( $p$ $<0.001$ by ANOVA). $B$, Metabolic inhibitors greatly decreased staining densities in terminal-rich layers of the slice. Both inhibitors produced significantly lowered densities in both layers. $C, \mathrm{~A}$ severe metabolic insult by dinitrophenol significantly decreased staining densities of granule cell layers. In contrast, a less severe insult by azide was unable to produce significant decreases in immunoreactivity of either the pyramidal cell or granule cell layers. ${ }^{*}, p<0.05$ from control by NewmanKuels multiple comparison test. In $B$ and $C$ each column represents the mean staining density of four sections taken from three separate immunocytochemical experiments processed on different days; error bars indicate SEM. $D N P$, dinitrophenol; $M$, stratum moleculare; $O$, stratum oriens: $G$, stratum granulare; $P$, stratum pyramidale.

Figure 14. GLIR in slices fixed immediately after cutting. A, Pyramidal cell perikarya (arrowheads) of CA1 and their dendrites (arrows) are intensely stained for Glu. Puncta in stratum radiatum $(R)$ and stratum oriens $(O)$ have not yet acquired intense labeling compared with surrounding structures. $B$, Many granule cells of the area dentata are intensely labeled (arrowheads). Puncta in the stratum moleculare $(M)$ have not yet acquired intense labeling compared to surrounding structures. $C$, Absorption control showing lack of staining of CAl when the monoclonal antibody to glutaraldehyde-fixed Glu is preincubated with Glu conjugated to bovine serum albumin. $P$, stratum pyramidale. Scale bars, $25 \mu \mathrm{m}$. 

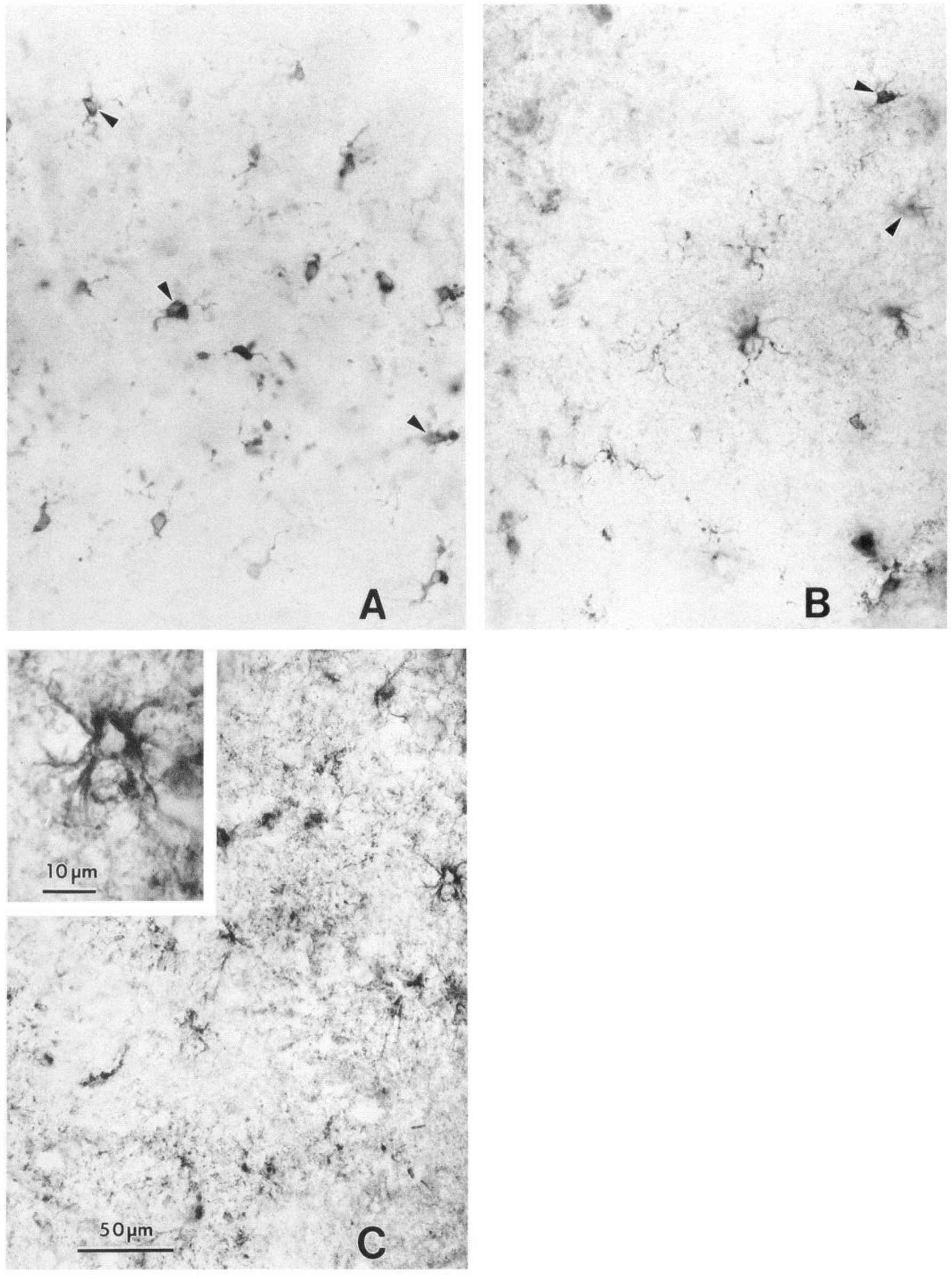
minals. It is likely that the $\mathrm{Na}^{+}$gradients of terminals can be more rapidly depleted than those of structures with larger volumes such pyramidal cell bodies. This hypothesis is consistent with the intermediate losses of GLIR seen in granule cells that are intermediate in size between pyramidal cells and terminals (Fig. 15).

\section{References}

Adam-Visi V (1992) External $\mathrm{Ca}^{2+}$-independent release of neurotransmitters. J Neurochem 58:395-405.

Anderson KJ, Monaghan DT, Bridges RJ, Tavoularis AL, Cotman CW (1990) Autoradiographic characterization of putative excitatory amino acid transport sites. Neuroscience 38:311-322.

Atkinson DE (1968) The energy charge of the adenylate pool as a regulatory parameter. Biochemistry 7:1030-1034.

Banks P, Bartley W, Birt LM (1976) Biochemistry of the tissues. London: Clowes.

Barbour B, Brew H, Attwell D (1991) Electrogenic uptake of glutamate and aspartate into glial cclls isolated from the salamander (Ambystoma) retina. J Physiol (Lond) 436:169-193.

Benveniste H, Drejer J, Schousboe A, Diemer NH (1984) Elevation of the extracellular concentrations of glutamate and aspartate in rat hippocampus during transient cerebral ischemia monitored by intracerebral microdialysis. J Neurochem 43:1369-1374.

Benveniste $H$, Jorgensen MB, Sandberg M, Christensen T, Hagberg $H$, Diemer NH (1989) Ischemic damage in hippocampal CAl is dependent on glutamate release and intact innervation from CA3. J Cereb Blood Flow Metab 9:629-639.

Bouvier M, Szatkowski M, Amato A, Attwell D (1992) The glial glutamate uptake carrier counterports $\mathrm{pH}$-changing anions. Nature 360:471-474.

Bridges RJ, Stanley MS, Anderson MW, Cotman CW, Chamberlin AR (1991) Conformationally defined neurotransmitter analogucs. Sclcctive inhibition of glutamate by one pyrrolidine-2,4-dicarboxylate diastereomer. J Med Chem 34:717-725.

Butcher SP, Sandberg M, Hagberg H, Hamberger A (1987) Cellular origins of endogenous amino acids released into the extracellular fluid of the rat striatum during severe insulin-induced hypoglycemia. $J$ Neurochem 48:722-728.

Choi DW (1988) Glutamate neurotoxicity and diseases of the nervous system. Neuron 1:623-634.

Dagani F, Erecinska M (1987) Relationships among ATP synthesis, $\mathrm{K}^{+}$gradients and neurotransmitter amino acid levels in isolated rat brain synaptosomes. J Neurochem 49:1229-1240.

Drejer J, Benveniste H, Diemer NH, Schousboe A (1985) Cellular origin of ischemic-induced glutamate release from brain tissue in vivo and in vilro. J Neurochem 45:145-151.

Englesen B, Fonnum F (1983) Effects of hypoglycemia on the transmitter pool and the metabolic pool of glutamate in the rat brain. Neurosci Lett 42:317-322.

Erecinska M (1987) The neurotransmitter amino acid transport systems. Biochem Pharmacol 36:3547-3555.

Erecinska M, Dagani F (1990) Relationship between the neuronal sodium/potassium pump and energy metabolism. J Gen Physiol 95: 591-615.

Fletcher EJ, Mewett KN, Drew CA, Allen RD, Johnston GA (1991) Inhibition of high affinity L-glutamic acid uptake into rat cortical synaptosomes by the conformationally restricted analogue of glutamic acid, cis-1-aminocyclobutane-1,3-dicarboxylic acid. Neurosci Lett 121: 133-135.

Fonnum F (1984) Glutamate: a neurotransmitter in mammalian brain. J Neurochem 42:1-11.

Glynn IA, Karlish SJD (1975) The sodium pump. Annu Rev Physiol 37:13-55.

Hagberg H, Andersson P, Lacarewicz J, Jacobson I, Butcher S, Sandberg
M (1987) Extracellular adenosine, inosine, hypoxanthine, and xanthine in relation to tissue nucleotides and purines in rat striatum during transient ischemia. J Neurochem 49:227-231.

Hansen AJ (1985) Effect of anoxia on ion distribution in the brain. Physiol Rev 65:101-148.

Hertz L, Drejer J, Schousboe A (1988) Energy metabolism in glutamatergic neurons, GABAergic neurons and astrocytes in primary cultures. Neurochem Res 13:605-610.

Jewell EA, Lingrel JB (1991) Comparison of the substrate dependence of the rat $\mathrm{Na}, \mathrm{K}$-ATPase $\alpha 1, \alpha 2$, and $\alpha 3$ isoforms expressed in $\mathrm{HeLa}$ cells. J Biol Chem 266:16925-16930.

Johnson GAR, Lodge D, Bornstein JC, Curtis DR (1980) Potentiation of L-glutamate and L-aspartate excitation of cat spinal neurones by the stereoisomers of threo-3-hydroxyaspartate. J Neurochem 34:241243.

Katayama Y, Kawamata T, Tamura T, Hovda DA, Becker DP, Tsubokawa $T$ (1991) Calcium-dependent glutamate release concomitant with massive potassium flux during cerebral ischemia in vivo. Brain Res 558:136-140.

Kauppinen RA, Nicholls DG (1986) The failure to maintain nerve terminal glycolysis in anoxia. $J$ Ncurochem 47:1864-1869.

Kauppinen RA, McMahon HT, Nicholls DG (1988) $\mathrm{Ca}^{2+}$-dependent and $\mathrm{Ca}^{2+}$-independent glutamate release, energy status and cytosolic free $\mathrm{Ca}^{2+}$ concentration in isolated nerve terminals following metabolic inhibition: possible relevance to hypoglycaemia and anoxia. Neuroscience 27:175-182.

Kish PE, Ueda T (1991) Calcium-dependent release of accumulated glutamate from synaptic vesicles within permeabilized nerve terminals. Neurosci Lett 122:179-182.

Lehninger AL (1975) Biochemistry. New York: Worth.

Lipton P, Whittingham TS (1979) The effect of hypoxia on evoked potentials in the in vitro hippocampus. J Physiol (Lond) 287:427438.

Lipton P, Whittingham TS (1982) Reduced ATP concentration as a basis for synaptic transmission failure during hypoxia in the in vitro guinea-pig hippocampus. J Physiol (Lond) 325:51-65.

Madl JE, Clements JR, Larson AA, Wenthold RJ, Beitz AJ (1988) Monoclonal antibody to glutamate dehydrogenase: localization in mitochondria of the cerebellar cortex. Brain Res 452:396-402.

McBean GJ, Roberts PJ (1985) Neurotoxicity of L-glutamate and DLthreo-3-hydroxyaspartate in the rat striatum. J Neurochem 44:247254.

McDonald AJ, Beitz AJ, Larson AA, Kuriyama R, Silletto C, Madl JE (1989) Co-localization of glutamate and tubulin in putative excitatory neurons of the hippocampus and amygdala: an immunohistochemical study using monoclonal antibodies. Neuroscience 30:405421.

McGrail KM, Phillips JM, Sweadner KJ (1991) Immunofluorescent localization of three $\mathrm{Na}, \mathrm{K}$-ATPase isozymes in the rat central nervous system: both neurons and glia can express more than one $\mathrm{Na}, \mathrm{K}$ ATPase. J Neurosci 11:381-391.

McMahon HT, Barrie AP, Lowe M, Nicholls DG (1989) Glutamate release from guinea-pig synaptosomes: stimulation by reuptake-induced depolarization. J Neurochem 53:71-79.

Naito S, Ueda T (1985) Characterization of glutamate uptake into synaptic vesicles. J Neurochem 44:99-109.

Ottersen OP, Storm-Mathisen J (1984) Glutamate- and GABA-containing neurons in the mouse and rat brain, as demonstrated with a new immunocytochemical technique. J Comp Neurol 229:374-392.

Ottersen OP, Storm-Mathisen J, Bramham C, Torp R, Laake J, Gundersen V (1990) A quantitative electron microscopic immunocytochemical study of the distribution and synaptic handling of glutamate in rat hippocampus. Prog Brain Res 83:99-1 14.

Pastuszko A, Wilson DF, Erecinska M (1982) Neurotransmitter metabolism in rat brain synaptosomes: effect of anoxia and pH. J Neurochem 38:1657-1667.

Robinson JD (1982) Transport ATPases. In: Handbook of neuro-

Figure 16. Effects of altering $\mathrm{Na}^{+}$and $\mathrm{K}^{+}$gradients on GLIR in the area dentata. $A$, High concentrations of $\mathrm{K}^{+}\left(60 \mathrm{mM}^{2}\right.$ produce similar decreased intensity of staining of puncta and increased intensity of staining of glial-like cells (arrowheads). $B$, Ouabain ( $500 \mu \mathrm{M})$ decreases intensity of staining of puncta and increases intensity of staining of cells with glial-like morphology (arrowheads). $C$, Veratridine ( $50 \mu \mathrm{M}$ ) also decreased labeling of puncta and increased intensity of labeling of glial-like cells. The inset shows a higher magnification of an intensely stained cell with typical astrocytelike morphology. Scale bars: $C, 50 \mu \mathrm{m}$ for $A-C$; inset, $10 \mu$. 
chemistry, Vol 5, 2d ed (Lajtha A, ed), pp 173-193. New York: Pergamon.

Robinson MB, Hunter-Ensor M, Sinor J (1991) Pharmacologically distinct sodium-dependent $\mathrm{L}-\left[{ }^{3} \mathrm{H}\right]$ glutamate transport processes in rat brain. Brain Res 544:196-202.

Rosen AS, Morris ME (1991) Depolarizing effects of anoxia on pyramidal cells of rat neocortex. Neurosci Lett 124:169-173.

Rothman SM, Olney JW (1986) Glutamate and the pathophysiology of hypoxic-ischemic brain damage. Ann Neurol 19:105-111.

Sandberg M, Butcher SP, Hagberg H (1986) Extracellular overflow of neuroactive amino acids during severe insulin-induced hypoglycemia: in vivo dialysis of the rat hippocampus. J Neurochem 47:178-184.

Skilling SR, Smullin DH, Beitz AJ, Larson AA (1988) Extracellular amino acid concentrations in the dorsal spinal cord of freely moving rats following veratridine and nociceptive stimulation. J Neurochem $51: 127-132$.

Stocchi A, Cucchiarini L, Canestrari F, Piacentini MP, Fornaini G (1987) A very fast inn-pair reversed-phase method for the separation of the most significant nucleotides and their degradation products in human red blood cells. Anal Biochem 167:181-190.

Storm-Mathisen J, Ottersen OP, Fu-Long T, Gundersen V, Laake JH, Nordbo $G$ (1986) Metabolism and transport of amino acids studied by immunocytochemistry. Med Biol 64:127-132.
Sweadner KJ (1989) Isozymes of the $\mathrm{Na}^{+} / \mathrm{K}^{+}$-ATPase. Biochem Biophys Acta $988: 185-220$.

Szatkowski M, Barbour B, Attwell D (1990) Non-vesicular release of glutamate from glial cells by reversed electrogenic glutamate uptake. Nature 348:443-446.

Van den Berg CJ (1978) A model of compartmentation in mouse brain based on glucose and acetate metabolism. In: Metabolic compartmentation in the brain (Balazs R, Cremer JE, eds), pp 137-166. New York: Wiley.

Wenthold RJ, Skaggs KK, Altschuler RA (1986) Immunocytochemical localization of aspartate aminotransferase and glutaminase immunoreactivities in the cerebellum. Brain Res 363:371-375.

Whittingham TS, Lust WD, Christakis DA, Passonneau JV (1984) Metabolic stability of hippocampal slice preparations during prolonged incubation. J Neurochem 43:689-695.

Wiklund L, Toggenburger G, Củenod M (1984) Selective retrograde labelling of the rat olivocerebellar climbing fiber system with D- $\left[{ }^{3} \mathrm{H}\right]$ aspartate. Neuroscience 13:441-468.

Wilson DF, Pastusko A (1986) Transport of cysteate by synaptosomes isolated from rat brain: evidence that it utilizes the same transporter as aspartate, glutamate, and cysteine sulfinate. J Neurochem 47:10911097. 